\title{
NEW METHODS FOR ESTIMATING LABOR SUPPLY FUNCTIONS: A SURVEY
}

\section{James J. Heckman}

Thomas E. MaCurdy

Working Paper No. $\underline{85}$

\section{NATIONAL BUREAU OF ECONOMIC RESEARCH 1050 Massachusetts Avenue \\ Cambridge MA 02138}

February 1982

This research was supported by NSF Grant SOC-77-27136 and Grant 10-P-9074819-01 from the Social Security Administration to NBER. This paper was presented at a conference on Labor Markets, Magdalen College, oxford, England, September, 1979. The research reported here is part of the NBER's research program in Labor Studies. Any opinions expressed are those of the authors and not those of the National Bureau of Economic Research. 
New Methods for Estimating Labor Supply Functions:

A Survey

Abstract

This paper surveys new methods for estimating labor suppIy functions. A unified framework of analysis is presented. All recent models of Iabor supply are special cases of a general index function model developed for the analysis of dumny endogenous variables.

Professor James J. Heckman Department of Economics University of Chicago 1126 East 59th Street Chicago, IL 60637

(312) $753-4533$ or -1106
Professor Thomas E, MaCurdy Department of Econonics Stanford University Stanford, California 94305

(415) $497-9694$ 


\section{Introduction}

Recent empirical studies of Iabor supply have their foundations 1n the statistical theory of "index functions." Thts theory offers a general methodology to correct for sample selection blases and provides a conceptually simple framework for wodeling corner solutions to the consumer's ut1lity maximizatton problem. In this survey we show how recent studies on labor supply dealing with the topics of labor force partictpation, fixed costs of work, and taxes can all be fit within a general "Index function framework."

The statistical theory of index functions has its foundation in the literature on dumy endogenous variables in a system of simultaneous equations. This 1fterature is based on the gotion that discrete endogenous variables are generated by continuous latent variables crossing thresholds. Tobin's (1958) seminal paper on estlmating the demand for consumer durables is the first application of index function theory in econoutes. In Tobin"s sodel, the fotenstry of demand for the durable good is the Index function. Due to population variation in reservation prices, many consumers are at corner solutions. OnIy if the intensity of demand exceeds some mintmum level (the threshold) does the individual purchase the durable good.

Over the past decade, the "index function framework" has been used extenstvely to analyze many problems in the area of consumer cholce, facluding the analysis of quantal (1.e., discrete) chotce (MeFadden, 1974, 1976 and Domencich and McFadden, 1976). This framework also forms the basis for recent work dealing with problems arising from the use of nonrandom samples and sample selection biases. A general discussion of index functions and thelr relationship to simultaneous equation models which incorporate 
both continuous and discrete varlables appears in Heckman (1978).

This survey begins with a discussion of the basic statistical framework found In many recent labor supply studies. In Section II we interpret leckman's (1974a) model of jolnt labor supply, participation, and wage rates within this framework. Section III considers extensions of this model to incorporate fixed costs associated with labor supply, and it interprets the studies of Cogan (1976, 1979), Hanoch (1976, 1979), and Hausman (1979). Section IV develops a basic model for analyzing progressive tax schemes and labor supply. In Section $V$ we generalize this model to allow for regressive as well as progressive raxes along the lines proposed by Burtless and Hausman (1978), Hausman (1979), and Wales and Woodland (1979). Discussion of specific methods of estimation is deferred to an appendix. 
I. The Basic Index Model

The prototype for all of the models considered in this paper is a simple binary cholce model. Let $V_{(1)}\left(R_{l}, v\right)$ be the best attainable utility for a consumer who does not work. $R_{1}$ is unearned income and $v$ is an unobserved "taste" component. Let $\nabla_{(2)}\left(R_{2}, W, v\right)$ be his best attainable utility given that he works. His get wage is $W$ and $R_{2}$ is his unearned income measured net of woney costs of work (and other money transactions costs). $R_{2}$ may differ from $R_{I}$ due to the presence of work-related fixed costs. The net wage is irrelevant in evaluating the utility of the no work state.

If $\mathrm{v}_{(2)}>\mathrm{v}_{(1)}$, the consumer works. Otherwise, he does not. Write $Y_{1}=v_{(2)}-v_{(1)}$, then if

$$
Y_{1}=\nabla_{(2)}-\nabla_{(1)}>0
$$

the consumer works. This condition, and closely related conditions, underlie much recent work in labor supply.

If the consumer works, one may define an hours of work equation for the consumer. If equilibrtum hours of work are determined by equating margtaal benefits of work with warginal costs, one may use Roy's 1dentity to derive the equation governing hours of work as

$$
H=\frac{\partial \nabla_{(2)}}{\partial W} / \frac{\partial \nabla_{(2)}}{\partial R_{2}}
$$

The hours of work equation may be written as 


$$
Y_{2}=\mathrm{H}\left(R_{2}, \mathrm{H}, \mathrm{v}\right)
$$

In the ensuing analysis, we use this notation for the hours of work equation even when the conditions required for the application of Roy's theorem no longer apply.

Condition (1) is a prototype of a class of sample selection conditions that has received considerable attention in the recent econometric 1iterature. In order to focus on the essential statistical 1ssues involved, consider two linear functions

$$
\begin{aligned}
& Y_{1}=z_{1} \beta_{1}+\varepsilon_{1} \\
& Y_{2}=z_{2} \beta_{2}+\varepsilon_{2} .
\end{aligned}
$$

$\varepsilon_{1}$ and $\varepsilon_{2}$ are thean zero random variables with finite second moments which are distributed Independently of the vectors $z_{1}$ and $z_{2}$. Suppose we seek to estimate $B_{2}$. However, we only have data on individuals in a sample for which $Y_{1}>0$.

The regression for $Y_{2}$ given $Z_{2}$ and $Y_{1}>0$ is

$$
\text { (4) } \begin{aligned}
E\left(Y_{2} \mid Z_{2}, Y_{1}>0\right) & =Z_{2} \beta_{2}+E\left(\varepsilon_{2} \mid Y_{1}>0\right) \\
& =Z_{2} \beta_{2}+E\left(\varepsilon_{2} \mid \varepsilon_{1}>-Z_{1} \beta_{1}\right) .
\end{aligned}
$$

If $\varepsilon_{1}$ and $\varepsilon_{2}$ are independent, $E\left(\varepsilon_{2} \mid \varepsilon_{1}>-z_{1} \beta_{1}\right)=0$. Otherwise, the conditional mean of $\varepsilon_{2}$ depends on $z_{1}$ and, in particular, on the probability that an observation with characteristics $Z_{1}$ is observed.

Write the joint density of $\varepsilon_{1}, \varepsilon_{2}$ as $f\left(\varepsilon_{1}, \varepsilon_{2} \mid \theta\right)$ where $\theta$ is a vector of parameters that generate the density. The probability that $Y_{1}>0$ is simply 


$$
I-F_{1}\left(-z_{1} \beta_{1} \mid \theta\right)=\int_{-\infty}^{\infty} \int_{-z_{1} \beta_{1}}^{\infty} E\left(\varepsilon_{1}, \varepsilon_{2} \mid \theta\right) d \varepsilon_{1} d \varepsilon_{2}
$$

where $F_{1}$ is the marginal distribution function of $E_{1}$. The conditional density of $\varepsilon_{2}$ given $Y_{1}>0$ is

$$
k\left(\varepsilon_{2} \mid \varepsilon_{1}>-z_{1} \beta_{1}, \theta\right)=\frac{\int_{-Z_{1} \beta_{1}}^{\infty} f\left(\varepsilon_{1}, \varepsilon_{2} \mid \theta\right) d \varepsilon_{1}}{1-F_{1}\left(-z_{1} \beta_{1} \mid \theta\right)} .
$$

Thus

$$
\begin{aligned}
E\left(\varepsilon_{2} \mid \varepsilon_{1}>-z_{1} \beta_{1}\right) & =\int_{-\infty}^{\infty} \varepsilon_{2} k\left(\varepsilon_{2} \mid \varepsilon_{1}>-z_{1} \beta_{1}, \theta\right) d \varepsilon_{2} \\
& \equiv g\left(-z_{1} \beta_{1}, \theta\right) ;
\end{aligned}
$$

and, so,

$$
E\left(Y_{2} \mid z_{2}, Y_{1}>0\right)=z_{2} \beta_{2}+g\left(-z_{1} \beta_{1}, \theta\right)
$$

A regression of $Y_{2}$ on $Z_{2}$ that 1gnores the sample selection rule omits the term $g(\cdot)$ from the regression and standard spectfication error arguments apply.

For example, consider a varlable $z_{2 j}$, that appears in both $z_{1}$ and $z_{2}$. Let $Y_{2}$ be hours of work. A regression of $Y_{2}$ on $Z_{2}$ that does not correct for the sample selection term $g$ estimates to a first order of approximation, instead of $B_{2 j}$, 


$$
\hat{\beta}_{2 j}=\beta_{2 j}+\frac{\partial g}{\partial z_{2 j}}
$$

The estimated value of $B_{2 j}$ differs from the true value by the second term on the Iight-hand side.

The essential point is that as we change $z_{2 j}$ we alter the effective composition of the sample of workers. Computed partial derivatives with respect to $z_{2 f}$ combine the ceteris paribus effect of changing $z_{2 j}$ holding castes fixed with the effect of changes in $z_{2 j}$ on altering the sample distribution of tastes for work. The sample distribution of tastes for work is the distribution of $\varepsilon$ conditional on condition (1) being met. This final effect is a consequence of entry and exit of observations from the sample due to the fact that condition (1) must be satisfied.

Conditton (1) encompasses two distinct 1deas which are sometimes confused in the 1iterature. The first idea is that of self-selection. An Individual chooses elther to work or not to work. From an inftial randow sample of consumers, a sample of workers is not random in view of condition (1). The second idea is a more general concept--that of sample selectionwhich includes the first idea as a special case. From an "Ideal" random sample, some rule is used to generate an observed sample of individuals. These riles may or way not be the consequences of cholces made by the consumers being studied. For example, in the negatfve income tax experiments, decisions were made to "experiment" on low income populations. The effect of this restriction is that a decision rule generates the observed samples of workers and nonworkers. Since earnings are generated, in part, by tastes for work, these restrlctions on sample membership operate on labor 
supply estimates based on selected samples in much the same way as condition (1). Econometric solutions to the general sample selection bias problem and the self-selection bias problem are identical. Much of the modern work on Female labor supply and the analysis of experlmental data, to be discussed below, is designed to elfminate the effects of sample selection bias on estimated structural labor supply functions.

The Index function model given by equations (2) - (5) underlies all of the recent work on truncation and sample selection. For example, Cain and Watts (1973, p. 343) and Hausman and W1se (1977) constder a censoring problem that arises in analyzing data from the Negative Income Tax experiments. Labor supply functions are ftt for expertmental participants. However, to be an experimental particlpant, earnings, E, are required to be below a certain cutoff level $\overline{\mathrm{E}}$. We thus observe individuals in the experiment only 1f $E<\vec{E}$. In terms of the index function models, we way write

$$
Y_{I}=\bar{E}-E \text {. }
$$

Write labor supply as $Y_{2}=Z_{2} B_{2}+\varepsilon_{2}$, We observe $Y_{2}$ only if $Y_{1} \geq 0$. Since it is plausible that the disturbances of the earaings function are not distributed independenty of the disturbances of the hours of work function, the analysis of equations (2) - (5) applies with full force to this case.

The index function model can readily be generalized to encompass a multiplicity of sample generation fules and a multiplicity of behavioral functions. $Y_{1}$ and $Y_{2}$ may be vectors, and the simultaneous satisfaction of a set of sample generation fules can be characterized by the requirement that $\mathrm{Y}_{1}$ lies in some subset of the feasible range of $\mathrm{Y}_{1}$. 
A version of the Index model that will occupy our attention below is one in which individuals may be in any one of m states of the world where the value of the random variable $Y_{1}$ determines the state. In particular, a consumer is in state 1 if $Y_{1}$ lies in a set $\theta_{i}$ which is some prespecifled subset of the sample space of $Y_{1}$. The labor supply of a consumer occupying state 1 is determined by a function $\mathrm{Y}_{2}=\mathrm{H}_{(i)}\left(\mathrm{R}_{1}, \mathrm{~W}_{1}, v\right)$. Thus, the function relevant for determining a consumer's hours of work is state dependent in the sense that its form and/or its argumeats differ across the various states. In the simple binary index model given by equations (1) - (3), there are two states of the world $(1, e ., I=2)$, and the sample space of $Y_{1}$ is divided 1nto two sets: $\theta_{1}=\left\{Y_{1}: Y_{1} \leq 0\right\}$ and. $\theta_{2}=\left\{Y_{1}: Y_{1}>0\right\}$. When in state 1 (i.e., $\left.Y_{1} \in \theta_{1}\right)$, a consumer's hours of work is given by $X_{2}=H_{1}=0$; and when in state 2 (i.e., $\left.Y_{1} \in \theta_{2}\right), Y_{2}=E_{2}=Z_{2} B_{2}+\varepsilon_{2}$.

All of the statistical models of labor supply to be considered below are spectal cases of this simple index function model. In the Heckman (1974a) model, there is a "work" and a "no work" state. $Y_{1}$ is the difference between the market wage and the reservation wage at zero hours of work. If $Y_{1}>0$, the consumer works. Given that he works, labor supply is defined as $Y_{2}=\frac{1}{Y} Y_{1}$ where $Y$ is a substitution parameter. The Cogan (1979) model of fixed costs is also a two-state model. $Y_{I}$ here is the difference betwean hours of work if the consumer is constrained to work and incur fixed costs, on the one hand, and "reservat1on hours" of work, on the other hand. If $Y_{1}>0$, the consumer chooses to work, and $Y_{2}$ is the hours of work chosen by the consumer. In the analysis of labor supply under progressive taxes where the budget constraint is composed of Iinear segments (due to discrete jumps in the marginal tax rate), each segment and klnk corresponds to a different state of the world. Thus, in 
contrast to the Heckman and Cogan models, there is more than one state associated with "work." $\mathrm{Y}_{1}$ is the marginal rate of substitution function, and as it takes values in various intervals, the consumer's labor supply equilibrium occurs on different branches of the budget constraint. While the hours of work function has the same forth for each of the work states, the arguments of the function are appropriately modified to reflect the different tax parameters facing consumers on the different branches and kinks of thelr budget constraints. The Burtless and Hausman (1978) modelof labor supply and taxes is general enough to deal with both regressive and progressive taxes. Their basic framework is the same as the one for the progressive tax case previousiy mentioned, except $Y_{I}$ in their model is an unobserved random "taste" component of the preference function. As $\mathrm{Y}_{1}$ falls in vartous regions, equilibrium occurs on different segments of the budget constraint. The index function models can accowodate a wide variety of errors in the variables, including errors that arise from the fnability to observe directly the particular state of the world a consumer occuptes. 
II. The Elementary Model of Labor Supply without Flxed Costs and Taxes

Consider a simple model of labor supply that neglects fixed costs of work and taxes. A consumer faces parametric wage ${ }^{1}{ }^{1}$ Let $X$ be a Hicks composite commodity of goods and $L$ a Hicks composite commodity of nonmarket time. The consumer's strictly quasiconcave preference function may be written as $U(X, L, v)$ where $v$ is a "taste shifter." For the population of consumers, the density of $v$ is written as $f(v)$. This function induces a distribution on $U$. The maximum amount of leisure is $T$. Income in the absence of work is $R$.

A consumer works only if his best work alternative is better than his best nonwork altemative (i.e., full lefsure). In the elementary model, a global compartson between the best attainable utilities in the work and no work states can be reduced to a local comparison between the marginal value of leisure at the no work position (the slope of the consumer's highest attainable Indifference curve at zero hours of work) and the wage rate.

The warginal rate of substitution is defined as

$$
M(R, Z, v)=\frac{\nabla_{2}(R+w A, I-H, v)}{U_{1}(R+W H, I-H, v)}
$$

where $B$ is hours of work and $X=R+W E$. The reservation wage is $M(R, 0, v)$. The consumer works if

$$
M(R, 0, v)<W
$$

otherwise, he does not. If condition (1) is satisfied, the labor supply function is determined by solving the equation $M(R, H, v)=W$ for $H$ to obtain 
(.8)

$$
\mathrm{H}=\mathrm{H}(\mathrm{R}, \mathrm{W}, v) \text {. }
$$

There are three distinct concepts of labor supply or expected hours of work that are often confused in the literature. Consider a population of consumers who all face offer wage $W$ and recelve unearned income $R$ but who have different $v$ 's. The density $f(v)$ determines the distribution of "tastes for work" over the population. One measure of labor supply is the fraction of the population that works. Letting $\theta$ denote the set of $v$ such that $M(R, 0, v)<W$, this fraction is

$$
P(W, R)=\int_{\theta} f(v) d v=\operatorname{Prob}(M(R, 0, v)<W)
$$

where $f_{\theta}$ denotes integrating over the set $\theta$. The mean hours worked for those employed is

$$
E(E) M(R, 0, v)<W)=\frac{\int_{\theta} H(R, W, v) f(v) d v}{P(W, R)} \text {. }
$$

Yet a third measure of labor supply is the mean hours worked in the entire population which is given by

$$
E(H)=\int_{\theta} H(R, \omega, v) E(v) d v
$$

(remember $H(R, W, v)=0$ for $v \theta \theta$. The three measures of labor supply depend on some of the same parameters, but they are clearly distinct. 
There is also some confuston in the literature concerning the appropriate interpretation of the partial derivatives of these different measures of labor supply. The partial derivatives of the hours of work function given by (8), $\mathrm{H}_{\mathrm{W}}$ and $\mathrm{H}_{\mathrm{R}}$, produce the textbook uncompensated wage and Income effects. It is crucial to note that these derivatives of $P(W, R)$ with respect to $W$ and $R$ do not correspond to $E_{W}$ and $E_{R}$ (Lew1s, 1967; Ben Porath, 1973). $P_{W}$ must be positive, and $E_{W}$ need not be. The partial derivatives of (10) or (I1) with respect to $W$ and $R$ do not correspond to the Hicks-Slutsky terms or $H_{R}$ unless condition (7) is satisfied for everyone in the population. These simple points have been 1gmored in much of the 1iterature. For example, Hall (1973) and Boskin (1973) Interpret the partial derivatives of estimates of equation (11) with respect to $h$ and $R$ as estimates of $E_{W}$ and $H_{R}$ respectively. Others tnterpret partfal derivatives of (IO) (estimated from labor supply functions fit on samples of working Individuals) as estimates of the HicksSlutsicy parameters. If nonparticipation is a significant phenomenon in the population being sampled, estimates of (IO) or (11) do not generate meaningful structural labor supply parameters. 2

The model of Heckman (1974a) can be witten within the index function Eramework. Write the marginal rate of substitution function given by (6) in semflog form as

$$
\text { la } M(R, E, v)=a_{0}+a_{1} R+a_{2} z_{2}+\gamma H+v
$$

where $v$ is a mean zero, normally distrtbuted error term. ${ }^{3}$ Market wage rates are written as 


$$
2 n=s_{0}+\beta_{1} z_{1}+v
$$

where $V$ is a normally distribuced error term wth mean zero. Solving equations (12) and (13) for hours of worts for thoge obserrations satisfying $2 \pi$ in $>2 \pi, 1(3,0,4)$, one obtalns

$$
\begin{aligned}
\exists & =\frac{1}{\gamma}(2 n w-2 n M(R, 0, \nu)) \\
& =\frac{1}{\gamma}\left(\beta_{0}+\beta_{1} z_{1}+v-a_{0}-a_{1} R-z_{2} z_{2}-\nu\right) \\
& =\frac{1}{Y}\left(\beta_{0}-a_{0}+\beta_{1} z_{1}-a_{1} R-z_{2} z_{2}\right)+\frac{1}{Y}(v-v) .
\end{aligned}
$$

In terms of the cro-equation index model,

$$
q_{1}=\ln W-2 \mathrm{M} M(R, 0, \nu)=\left(s_{0}-a_{0}+\beta_{1} z_{2}-x_{1} z-x_{2} z_{2}\right)-(\gamma-\nu)
$$

$$
Y_{2}=E=\frac{1}{Y} Y_{1}
$$

so that the parameters of the sample selection rule $\left(Y_{1}>0\right.$ ) are intizarely related to the labor supply function. Assuming that, and 7 are toin: notmally distributed, equations (13) and (14) generalize the "Tooi=" Dodel proposed by Tobin (1958). Provided that one variade appears Ia (12) siat does not appear in (13), y can be identikied jy a waximu Iikelíood procesura or a tro-stage procedure.

He note, parenthettcally, that if sost data sets on labor suppiy, =he condition that $Y_{1}>0$ must also be satistied in orter $=0$ josere tie rage rate. Estimates of wage Eunctions $\vdots i=$ on samples $2 \pm$ rockers are siojec: =0 the same sort of sample seiection bias that contamiates Laboz suppip zuncticns 
fit on subsamples of workers (Gronau, 1973). Assuming normally distributed error components, Heckman (1974a) builds a model that incorporates an hours of work equation (14) and a wage equation (13) that explicitly corrects for the effect of the condition $(\ell n W>\ln M(R, 0, v)$ ) on generating observations on workers. 


\section{Labor Supply Models with Flxed Costs}

Cogan (1976, 1979) and Hanoch (1976, 1979) extend the simple model of the previous section by allowing for a nonconvex choice set arising from flyed costs of work such as comwuting costs, expenditures on clothes needed for work, etc. The motivation for latroducing fixed costs is to account for the small number of observations near zero in the hours of work distributions computed for workers. Our exposition follows more closely the work of Cogan.

Consider Figure I. A consuner's no work indifference curve is given by RA. For the simple wodel described above, if the wage rate is given by the slope of RC, the consumer works, and a standard interior solution labor supply function is generated. If the wage rate is given by the slope of line RB, the consumer does not work. The introduction of fixed money costs of work means that the consumer must pay fixed money cost $F$ in order to work. The breakeven wage, which causes the consumer to be indfferent between work (with the fixed cost) and no work, is given by the slope of the line connecting points $R-F$ and $D$. If the consumer Is given a wage with this slope, and works $\mathrm{G}_{\mathrm{d}}$ hours, he is indifferent between work and nonwork. At any higher wage rate, he will work. As money costs are thcreased, so are reservation wage rates and the minimum number of hours that the consumer works if he works at a11. The relevant reservation wage for labor supply is the slope of indifference curve RA at position $D$.

The labor supply curve thus has a discontinuity. The consumer either does not work at all or works at least $\mathrm{B}_{d}$ hours. " $\mathrm{H}_{d}{ }^{\prime}$ is called "reservation hours" in the Iiterature. The slope of the no work 1ndifference curve at $\mathrm{H}_{\mathrm{d}}$ hours, $w_{d}$, is termed the reservation wage. The labor supply function for those who work is essentially a standard labor supply curve with unearned incowe $R$ reduced by amount $F$, the fixed money sosts of work. 


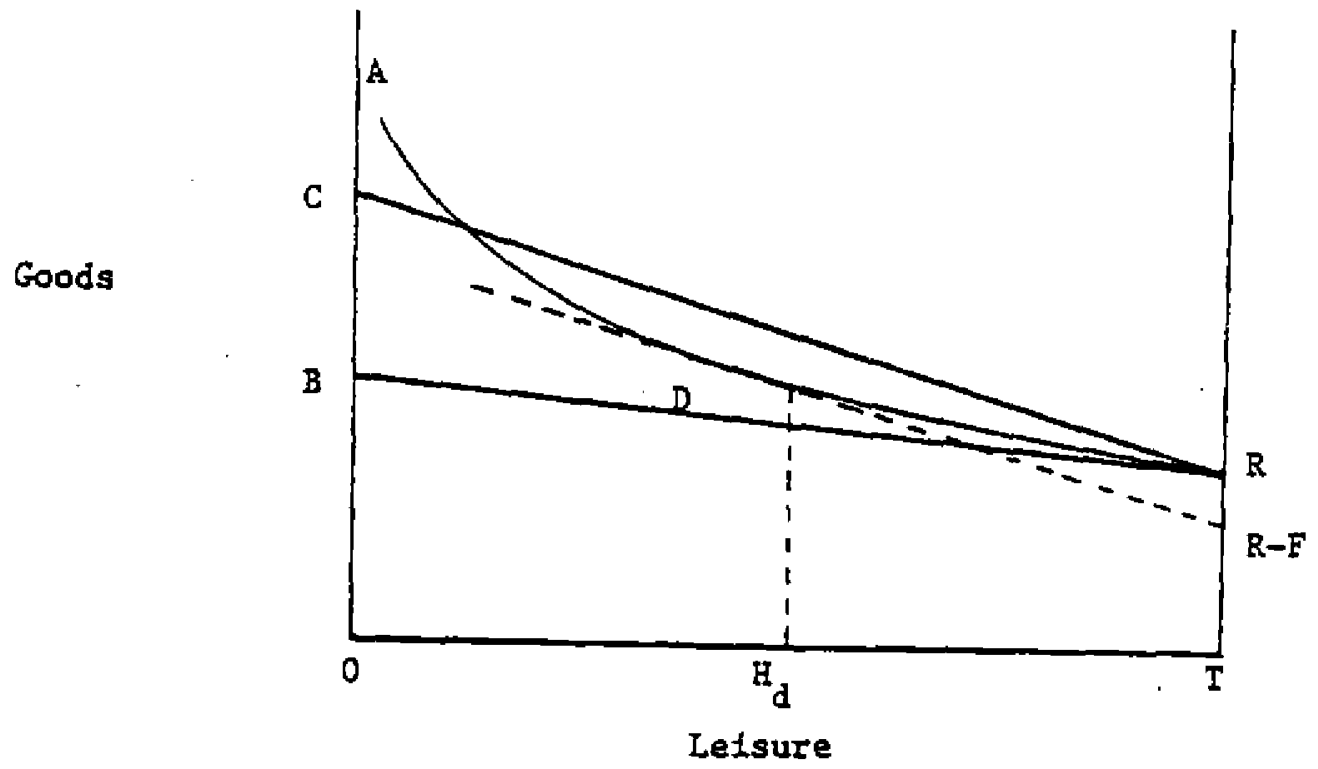

F1gure I

The analysis of fixed time costs of work parallels our discussion of Eixed money costs of work except that time costs reduce hours worked by working ladividuals while money costs increase hours worked by working individuals (assuming leisure is a normal good). No new idea is involved. The most direct way to solve for $W_{d}$ and $H_{d}$ is to use the indirect ut1lify function. "W $W_{d}$ Is defined as that value of $W$ such that

$$
V\left(R-F, W_{d}, v\right)=U(R, T, v)
$$

1.e., that value of $W_{d}$ such that given the fixed costs of work, $\bar{F}$, the consumer is tadifferent between working at wage $w_{d}$ and not working at all. This is the procedure used by Cogan (1979).

From equation (16) one can solve for $W_{d}$ and by Roy's Identity one can solve for ' $d$ ' 


$$
\mathrm{H}_{\mathrm{d}}=\frac{\mathrm{V}_{\mathrm{W}}}{\mathrm{V}_{\mathrm{R}}} .
$$

Thus one can write

$$
\begin{aligned}
H_{d} & =H_{d}(R, F, v) \\
W_{d} & =W_{d}(R, F, v) \\
H & =H(R-F, W, v) .
\end{aligned}
$$

Since the $H_{d}, W_{d}$, and $B$ functions are derlved from a comon utility function, cross-equation restrictions connect these three functions. Without assuming explfeit functional forms for the utility function it is difficult to impose these restrictions. Cogan does not impose a spectfic functional form and so does not explott all the available information in the system. In practice, one does not have data on fixed costs. F is assumed to depend on a large set of observed varfables, some of which do not enter the labor supply equation in their own right.

The consumer works provided that

$$
\mathrm{H}>\mathrm{E}_{\mathrm{d}} \text {. }
$$

In terms of the index function model, we may write

$$
\begin{aligned}
& \mathrm{Y}_{1}=\mathrm{H}-\mathrm{H}_{\mathrm{d}} \\
& \mathrm{Y}_{2}=\mathrm{H} .
\end{aligned}
$$


Thus we observe $Y_{2}$ only when $Y_{1}>0$.

Using standard sample selection bias correction procedures it is posstble to obtain estimates of the parameters of the $\mathrm{H}$ function. Assuming a functional form for $H$ and $H_{d}$, writing $H=H_{d}$ in reduced form, and assuming that one variable appears in $\mathrm{H}$ that does not appear in $\mathrm{H}_{\mathrm{d}}$ (e.g., the wage rate), It is possible to estimate the $\mathrm{H}_{\mathrm{d}}$ function from the reduced form probability that the consumer works if the sample at hand contains both workers and nonworkers. Thus, if

$$
\begin{aligned}
& H=Z \beta+W_{\gamma}+\varepsilon_{1} \\
& H_{d}=Z_{\phi}+\varepsilon_{2}
\end{aligned}
$$

where $Z$ is a set of exogenous variables, we have $H-H_{d}=Z(B-\phi)+W \gamma+\varepsilon_{1}-$ $\varepsilon_{2}$. Assuring that $\varepsilon_{1}-\varepsilon_{2}$ is normally distributed, the probability that

$\mathrm{H}-\mathrm{H}_{\mathrm{d}}>\mathrm{O}$ is a probit probability. From probit analysis it is possible to estimate $\frac{(\beta-\phi)}{\left[\operatorname{Var}\left(\varepsilon_{1}-\varepsilon_{2}\right)\right]^{\frac{1}{2}}}$ and $\frac{\gamma}{\left[\operatorname{Var}\left(\varepsilon_{1}-\varepsilon_{2}\right)\right]^{\frac{1}{2}}}$. Combining these estimates with those of $B$ and $\gamma$ from the hours of work function, one can estimate $\phi$.

All of the tests for the presence or absence of fixed costs that have been conducted within the Cogan framework have taken the Heckmen (1974a) specification given by equations (13) and (14) as the baseline model of labor supply without fixed costs. This model assues a strict proportionality relationship between the $\mathrm{H}$ and the $\mathrm{H}-\mathrm{H}_{\mathrm{d}}$ equations (i.e., between the $\mathrm{Y}_{1}$ and the $\mathrm{Y}_{2}$ indices). The simple Heckman specification of the labor supply curve may be drawn as $B B^{\prime}$ in Figure 2. The intercept of the function is the log of the reservation 
wage. The key point of Cogan's analysis is that with fixed money costs of work, the labor supply function looks like CC'C". The $10 \mathrm{~g}$ reservation wage is higher than $B$, a working consumer works at least $H_{d}$ hours, and the labor supply function is above the Heckman function (because leisure is assumed to be a normal good). If CC'C' is the true labor supply function, and the linear Heckman function is fit to the data, labor supply elastictties will be overstated because the intercept in the linear Eeckman labor supply curve is the reservation wage. Cogan's test for the presence of fixed costs amounts to determining whether the curve $C^{\prime} C^{\prime \prime}$ explains the data signficanty better than the curve $\mathrm{BB}^{\prime}$; If it does, then there are fixed costs associated with working.

Cogan's test crucially depends on an assumed functional form for the labor supply equation given by (14). If one permits nonlinearities In the log wage rate vartable in this equation, then a nonlinear curve like BD in Figure 2 is also consistent with the proportionality assumption (see Heckman (19746) for such an analysis). For all practical purposes this nonlinearity captures the essential features of Cogan's spectfication; namely, most consumers work a large number of hours if they work at all. Fixed costs may make a Ingear model of labor supply into a nonlfnear model, but there are many reasons for nonlinearity. Tests for proportionalfty are more appropriately interpreted as tests for the presence or absence of nonlineartity in labor supply functions. Fixed costs are a source of nonlfuearities, but evidence for or against nonlinearity is certainly not evidence for or against ifxed costs. Bausman (1979) extends Cogan's analysis of fixed costs by utilizing crossequation restrictions on the $\mathrm{H}$ and $\mathrm{H}_{\mathrm{d}}$ equations, and by utilizing another piece of information that Cogan neglects: that the position of the indifference 


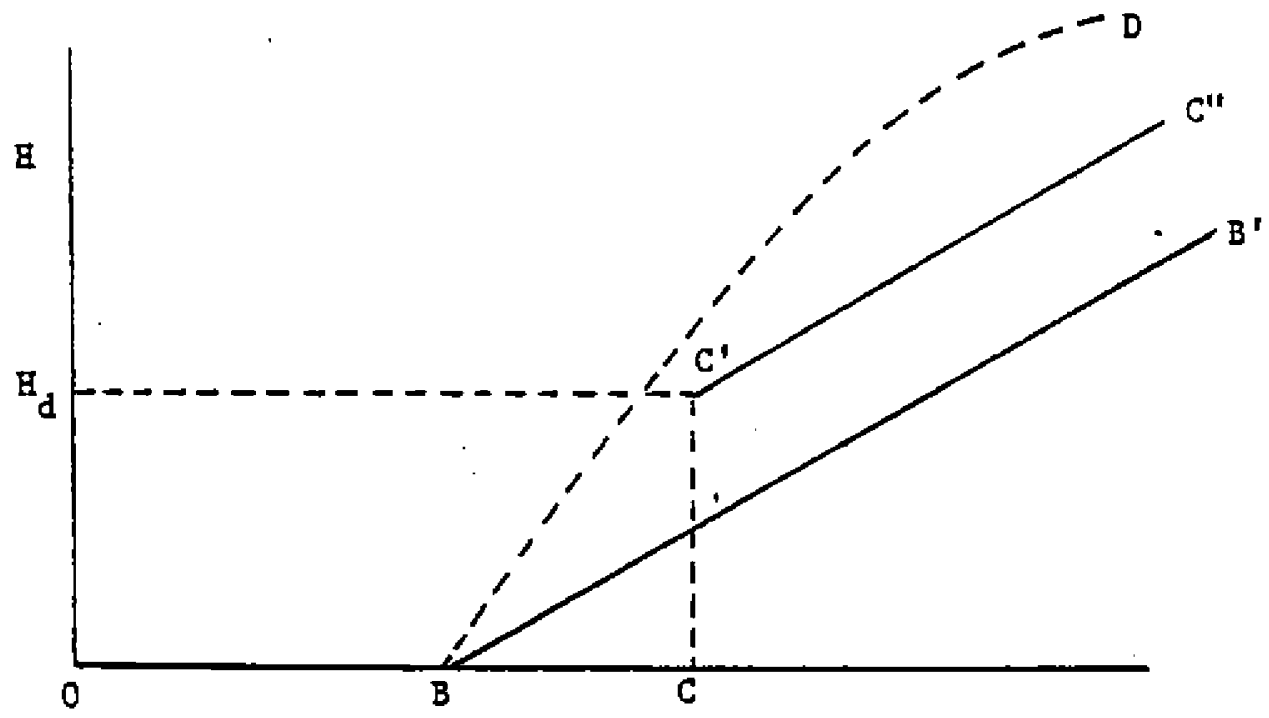

\& $\mathrm{W}$

Ffgure 2

curve for nonworkers does not depend on fixed costs. Uttlizing this information, he is able to estimate income and substitution effects of labor supply using only participation data. The price of these achlevements is the impostition of stringent functional forms for preferences and assumptions about the way unobservables enter the model.

The utility of the consumer in the no work position is $U(R, T, V)$. Using the indirect utflity function $\nabla(R-F, W, V)$, Hausman is able to locate the best work alternative. It is possible that the indirect utility function is not defined for certain values of $R, F, W$ and $v$, but for such a case, the consumer does not work.

Hausman's specification of unobserved heterogenefty $v$ is strong but leads to econometrically useful results. Onder his assumptions, $U, V$, and their difference, $U-V$, are monotonic functions of $v$, a scalar random variable. Given $W, R$ and an exace function for $F$ (so that fixed costs are 
a function solely of observed variables), Hausman can divide the domain of $v$ into two regions: a work region and a no work region. The boundary point for the region is given by $v^{*}$ which satisfies

$$
V\left(R-F, W, v^{*}\right)=U\left(R, T, v^{*}\right) \text {. }
$$

Preferences are defined so that for $v>v^{*}$ the consumer works (i.e., $v(R-F, W, v)>U(R, T, v))$, and for $v \leq v^{*}$ the consumer does not work (i.e., $\mathrm{V}(\mathrm{R}-\mathrm{F}, \mathrm{W}, \mathrm{v}) \leq \mathrm{U}(\mathrm{R}, \mathrm{T}, \nu))$.

For each set of parameters (of $V$ and $U$ ) and given $R$, $W$, and his assumed function for $F$, Hausman writes

$$
\mathrm{Y}_{1}=\mathrm{V}-\mathrm{U}
$$

where $\mathrm{Y}_{1}$ corresponds to the index function of equation (2). The probability of participation is simply the probability that $\mathrm{Y}_{1} \geq 0$. Given a distribution of "tastes," $f(v)$, the probability of working is

$$
\int_{v *}^{\infty} f(v) d v=\operatorname{Prob}\left(Y_{1}>0\right) .
$$

A comwon set of parameters generate $U$ and $V$. Hausman is able to estimate all of the parameters of the functions, and hence can generate all of the labor supply parameters, including income and substitution parameters, using only participation data. He is able to extract as much information as Cogan using less data because he assumes that the same linear labor supply function applies to the entire preference map, whereas Cogan uses a Iinear specification 
only as an approximation for the labor supply function for workers. However, given hours of work data, his procedure produces no more information than the Cogan procedure.

Two key assumptions in Hausman's model not needed in Cogan's, are:

(1) flxed costs components are perfectly predicted by measured variables, and (2) data on wage rates are avallable for all individuals in the sample (including nonworkers). - If either of these assumptions is violated, a more Involved procedure is required which amounts to solving for $u$ t given the mobserved components of $F$ and of $W$ and 1ntegrating over both these unobserved components. While it is conceivable that Hausman's Elrst assumption concerning the perfect measurability of $F$ is true, his second requirement concersing the avallability of data of offer wages for nonworkers is surely violated for most data sets. We defer discussion of the consequences of not being able to observe wages for some individuals until Section $\nabla$, where we develop a general Eramework for deal1ng wth such unobservables. 


\section{Labor Supply Models with Progressive Taxes}

In this section we extend the simple model of hours of work without fixed costs outlined in Section II to incorporate progressive caxes. In contrast to the models of labor supply discussed above where there are two posstble states of the world (i.e., work or no work), here we consider a multistate model. Although thig extended model cannot be readily applied to the regressive tax case, it provides the essential ingredients required to analyze the general case.

Provided that the tax function facting the consumer generates a continuously differentiable strictly convex constraint set, the introduction of taxes into the model poses few analytical difficulties. 1 Define after-tax income as

$$
E=E(H E+R ; \phi), \quad E^{\prime}>0, E^{\prime \prime}<0,
$$

where $\psi$ is a vector of parameters of the tax function (1ncluding exemption parameters and the like). The warginal wage rate at zero hours of work is

$$
\left.\frac{\partial E}{\partial B}\right|_{B=0}=E^{\prime}(R ; \psi) \text {. }
$$

Replacing $E^{\prime}(R ; \psi)$ for $W$ in conditton ( 7$)$, the analysis of labor force participation is the same as that given beiore. If the modifled participation condition is met, one can linearize the budget constraint around the equilibrium hours of work position and solve for the structural labor supply equation in terms of the equilibrium marginal wage $\Sigma^{\prime}(k \mathbb{H}+R ; \psi$ ) and the 
Intercept of the linearized budget constraint at the zero hours of work position, $E(W A+R ; \psi)-E^{\prime}(W H+R ; \psi) H$. The marginal wage replaces the gross wage in equation $(8)$, and the intercept term replaces $R$ in the equation.

We may write the structural labor supply equation as

$$
H=H\left(E^{\prime}, E-E^{\prime} H, v\right) \text {. }
$$

If labor supply is measured with error, or there are disturbances in the labor supply equation, one must instrument the marglaal wage and intercept terms of the linearbzed budget constraint to achieve consistent estimates, 2,3 This analysis cacrles over fully to estimation of labor supply functions in the presence of an equilibrium wage-hours locus (or hedonic 1ine) of the sort consldered by Lewis (1969) and Rosen (1974) provided that the constraint set facing the consumer is continuous and convex. 4

The fastitutional features of the U.S. tax system are such that the assumption of smooth, continuously differentiable constraint sets for aftercax iacome is counterfactual. The U.S. tax system induces kinks and flats in the post-tax income function. A progressive tax system generates a convex budget set with linear segments and kinks such as the one depicted in Figure 3. To simplify the exposition, we consider only a two-flat function. The ensuing analysis may easily be extended to a multiple kink constraint. Given Intitial income (after tax) of $R_{2}$, and a gross wage rate $\omega$, after-tax income in the presence of a kinked tax schedule may be characterized by a marginal tax rate of $t_{A}$ on the first segrient, $(0, \bar{H})$, and a higher marginal tax rate $t_{B}$ on the second segment, $(\bar{H}, T)$. 


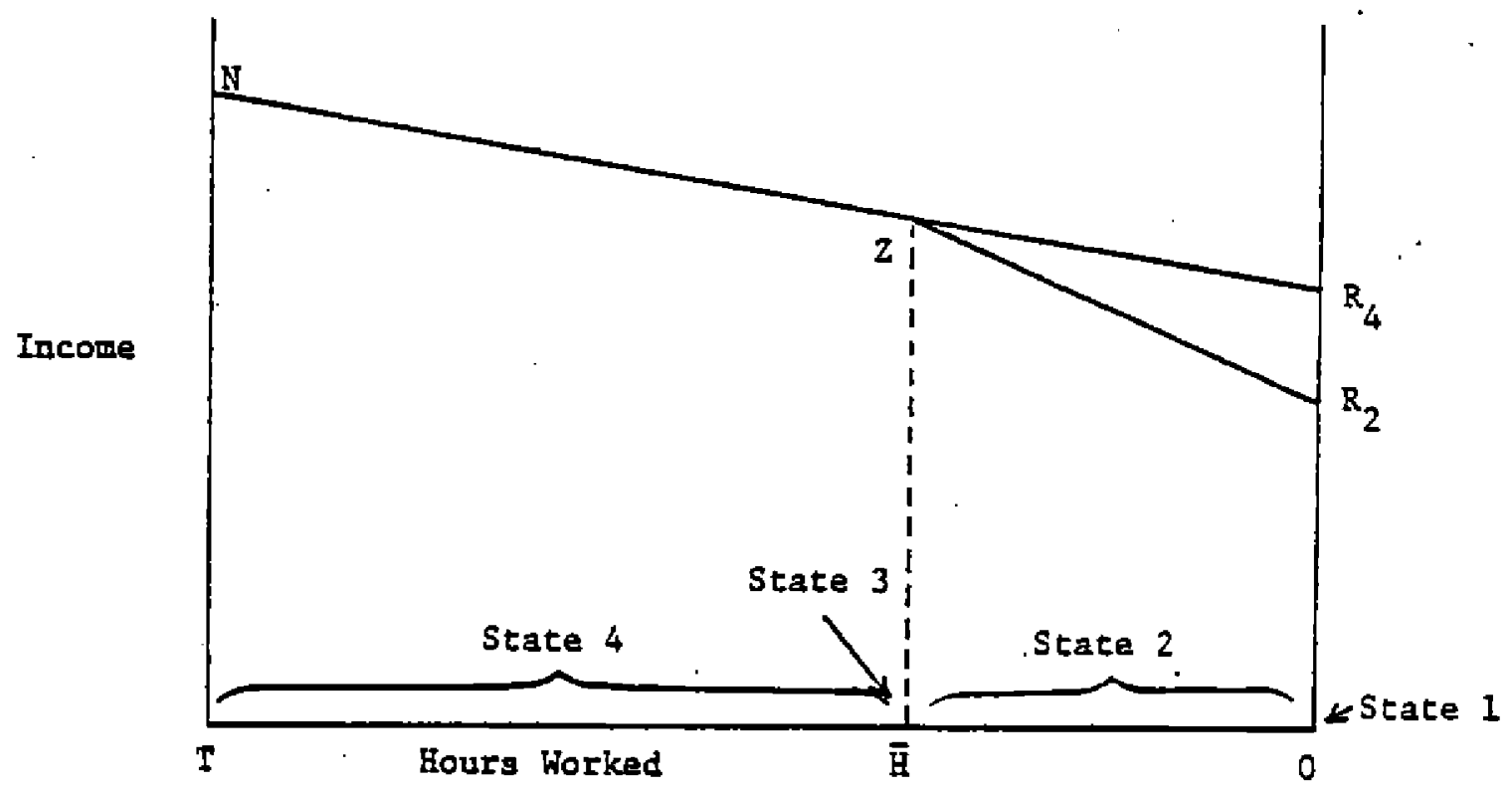

Figure 3

A consumer may occupy any one of four states of the world in this model of taxes. Each state corresponds to a different kink or segment of the budget constraint. A consumer who does not work is at kink point $R_{2}$ which congtitutes state 1. A consumer who chooses to work, on the other hand, may be on segment $R_{2} z$, or at kink point $z$, or on segment $z N$, which constitute states 2, 3, and 4, respectively. A consumer in state 2 faces a net marginal wage rate equal to $W_{2} \equiv W\left(1-t_{A}\right)$ and receives unearned income $R_{2}$. A consumer In state 4 , on the other hand, faces an after-tax wage race equal to $w_{4} \equiv$ $W\left(I-t_{B}\right)$ and can be vlewed as receiving the equivalent of $R_{4}=R_{2}+\left(W_{2}-W_{4}\right) \vec{B}=$ $R_{2}+W\left(t_{B}-t_{A}\right) \bar{H}$ as unearned 1ncome.

As a consequence of convexity of preferences and the constraint set, a local comparison of the marginal rate of substitution function given by (6) and the after-tax wage rate at the kink points decernines the location of an Individual on the budget set. The consumer chooses not to work if 
(17)

$$
M\left(R_{2}, 0, v\right) \geq W_{2} \equiv W\left(1-t_{A}\right)
$$

The consumer works in the interval $(0, \overline{\mathrm{H}})$ if-

$$
M\left(R_{2}, 0, v\right)<W_{2} \text { and } M\left(R_{4}, \vec{a}, v\right)>W_{2} .
$$

The consumer is in corner solution equilibrium at the kink $Z$ provided that

$$
w_{2} \geq M\left(R_{4}, \bar{y}, v\right) \geq W_{4} \equiv w\left(1-t_{B}\right) .
$$

Finaliy, the consumer is at an interior solution in the interval $(\overline{\mathrm{B}}, \mathrm{T})$ if

$$
M\left(R_{4}, \bar{B}, v\right)<W_{4} .
$$

It is straightforward to derive the implied labor supply function associated with each state of the world. To simplify the following exposition denote chis function by $\mathrm{H}_{(1)}$ for state 1 . In state 1 , the no work state, obviously $\mathrm{H}_{(1)}=0$. At interlor equilibrium on branch $R_{I} Z$, the labor supply function is determined by solving the equation $M\left(R_{2}, H_{(2)}, v\right)=W_{2} \equiv W\left(1-t_{A}\right)$ for $\mathrm{H}_{(2)}$; so, in state 2 hours of work is given by

$$
\mathrm{B}_{(2)}=\mathrm{H}\left(\mathrm{R}_{2}, \mathrm{~W}_{2}, v\right) \text {. }
$$

Io state 3 , the corner equflibrium at $\mathrm{z}, \mathrm{H}_{(3)}=\overrightarrow{\mathrm{H}}$. Finally, in state 4 (an interlor equilibrium along branch $2 N$ ), solving $M\left(R_{4}, H_{(4)}, V\right)=W_{4} \equiv$ $W\left(1-t_{B}\right)$ for $H_{(4)}$ implies a labor supply function of the form 


$$
\mathrm{H}_{(4)}=\mathrm{H}\left(\mathrm{R}_{4}, \mathrm{~W}_{4}, v\right) \text {. }
$$

While the functional form of the labor supply functions in states 2 and 4 1s the same, the arguments of these functions differ as a consequence of the different tax rates facing consumers on the different branches of the budget constraint.

To set up this model as an index function model, the "taste shifter" component, $v$, is a natural candidate for the Index $Y_{1}$ to determine which state of the world the consumer occuples. For given values of $R_{1}, W, \bar{H}, t_{A}$, and $t_{B}$, the consumer chooses one of the four possible states depending on the region 1 which $v$ lies. The conditions relating $M\left(R_{2}, 0, v\right)$ and $M\left(R_{4}, \overline{\mathrm{H}}, v\right)$ to after-tax wage rates I1sted above deftre these regtons. Let $\theta_{1}$, $\theta_{2}, \theta_{3}$ and $\theta_{4}$ denote the subsets of the sample space of $v$ that satisfy conditions $(17)-(20)$, respectively. If $v \in \theta_{1}$ (1.e., $v$ is an element of the set $\theta_{1}$ ), the consumer chooses state 1 .

If we assume that the marginal rate of substitution function, $M(R, H, V)$, is monotonicaliy increasing in $v$, we obtain simple expressions for these sets. Each $\theta_{1}$ is a single interval in the real line. Define $v_{1}^{*}, v_{2}^{*}$, and $v_{3}^{*}$ as those values of $v$ satisfying

$$
\begin{aligned}
& M\left(R_{2}, 0, v_{3}^{*}\right)=W_{2} \equiv W\left(1-t_{A}\right) \\
& M\left(R_{4}, \bar{B}, v_{2}^{*}\right)=W_{2} \\
& M\left(R_{4}, \bar{B}, v_{1}^{*}\right)=W_{4} \equiv W\left(1-t_{B}\right) .
\end{aligned}
$$

Convextty of preferences implies that $M\left(R_{4}, \bar{H}, v\right)>M\left(R_{2}, 0, v\right)$. Hence the monotonfelty assumption 1mplies that $v_{1}^{k}<v_{2}^{*}<v_{3}^{*}$. Conditions $(17)-(20)$, then, define the regions as 
$\theta_{1}=\left\{v: v_{3}^{*} \leq v\right\} ; \theta_{2}=\left\{v: v_{2}^{*}<v<v_{3}^{*}\right\} ; \theta_{2}=\left\{v: v_{1}^{*} \leq v \leq v_{2}^{*}\right\}$; and $\theta_{4}=$ $\left\{v: v<v_{1}^{*}\right\}$.

Choosing a spectification for the marginal rate of substitution function and a distribution for "tastes" in the population, $f(v)$, yields a complete scatistical characterization of labor supply behavior. The probability that a consumer is in state 1 is

$$
\operatorname{Prob}\left(v \in \theta_{i}\right)=\int_{\theta_{1}} E(v) d v \text {. }
$$

The expected hours of work of a consumer who is known to be 1 n state $i$ is

$$
\begin{aligned}
E\left(\mathrm{H} \mid \nu \mathrm{e} \theta_{1}\right) & =E\left(\mathrm{H}_{(1)} \mid v \in \theta_{i}\right) \\
& =\frac{\int_{\theta_{1}}{ }_{(1)} f(\nu) d \nu}{\text { Prob }\left(\nu \in \theta_{1}\right)}
\end{aligned}
$$

The expected hours of work for a randomly chosen individual is

$$
E(B)=\sum_{1=1}^{4} E\left(H_{(i)} \mid v \in \theta_{i}\right) \operatorname{Prob}\left(v \in \theta_{1}\right) \text {. }
$$

Estimation of structural labor supply perameters involves the same set of Issues considered in the simple Heckman model except that instead of the single corner and single interior solution segpents as in the Heckman model, there are two corners and two interlor segments in the model with kinked progressive taxes considered here. In order to avold sample selection bias 
1n estimating structural labor supply functions, one must account for the conditioning that generates the observations (i.e., one must account for the particular branch or corner on whtch an observation is sttuated). It is . obrious that, in this case, correcting for potential sample selection bias automatically corrects for the endogeneity in tax rates and unearned income levels. Indeed, in this model, endogenelty of taxes and sample selection blas come to the same thing.

To 1llustrate the procedure involved, consider the following empirical specification. Write $M(R, E, v)$ as

$$
M(R, A, v)=m_{0}+m_{1} R+m_{2} H+v \text {. }
$$

Since $M$ is monotonically increasing in $v$, the formulas for $v_{1}^{*}, v_{2}^{*}$, and $v_{3}^{*}$ given by (23) provide a simple method for dividing the sample space of $v$ into the sets $\theta_{i}$. We obtain

$$
\begin{aligned}
& v_{1}^{*}=w_{4}-m_{0}-m_{1} R_{4}-m_{2} \bar{B} \\
& v_{2}^{*}=w_{2}-m_{0}-m_{1} R_{4}-m_{2} \bar{H}-v_{1}^{*}+w\left(t_{B}-t_{A}\right) \\
& v_{3}^{*}=w_{2}-m_{0}-m_{1} R_{2}=v_{2}^{*}+m_{1}\left(R_{4}-R_{2}\right)+m_{2} \bar{H}
\end{aligned}
$$

The probabtlity that the consumer does not work is

$$
P \operatorname{zob}\left(v \geq v_{3}^{*}\right)=\int_{v_{3}^{*}}^{\infty} f(v) d v=1-F\left(v_{3}^{*}\right)
$$


where $F$ is the cumulative distribution function of $v$. The probability that the consumer is at interfor equflibrfum on the first segment, $R Z$, is

$$
\operatorname{Prob}\left(v_{2}^{*}<v<v_{3}^{*}\right)=\int_{v_{2}^{*}}^{v_{3}^{*}} f(v) d v=F\left(v_{3}^{*}\right)-F\left(v_{2}^{*}\right) \text {. }
$$

The probability of kink equilibrium at $Z$ is

$$
\operatorname{Prob}\left(v_{1}^{*} \leq v \leq v_{2}^{*}\right)=\int_{v_{1}^{*}}^{v_{2}^{*}} f(v) d v=F\left(v_{2}^{*}\right)-F\left(v_{1}^{*}\right)
$$

The probability of interior equilibrium along branch $2 \mathrm{~N}$ is

$$
\operatorname{Prob}\left(v<v_{1}^{*}\right)=\int_{-\infty}^{v_{1}^{*}} f(v) d v=F\left(v_{1}^{*}\right)
$$

An Important assumption of this version of the model is that ane can directly observe the state of the world each consumer occupies. Rnowledge of a consumer's hours of work is all the information required. If $\mathrm{H}=0$, the consumer is in state 1 ; if $\mathrm{H} \in(0, \overline{\mathrm{H}})$, he $1 \mathrm{~s}$ in state 2 ; if $\mathrm{H}=\overline{\mathrm{H}}$, he is in state 3; and if $\mathrm{E} \varepsilon(\overline{\mathrm{H}}, \mathrm{T})$, the consumer occuples state 4. By choosing a density function $f(v)$, it is possible to estimate directy the structural parameters determining the probabilitles of each state of the world given by (29) - (32).

If we choose $f(v)$ as the normal density, this statistical model is an ordered problt scheme (see Johnson (1972) and Rossett-Nelson (1975)). Forming the sample likelthood, one can estimate all. the parameters of the marginal 
rate of substitution function, and the variance of $v$. (The variance of $v$, $\sigma^{2}$, Is estimated by nommalizing by the standard deviation within each probability statement, and noting that the coefficient on $(I-t) w$ is $1 / \sigma$. The parameter $m_{2}$ is Identified if the kink point in the aftertax income function comes at different hours of work for different consumers-which, plausibly, is the case.)

Since the parameters of the $M$ function generate all of the parameters of the labor supply function, the ordered probit analysts suffices to determine the parameters of the labor supply function without using any data on hours of work. Given these probabilities, one can compute the conditional means of the interior solution of the hours of work function for each branch of the budget constraint and, by following a straightforward generalization of equation (5), achleve more efficlent estimates of the labor supply parameters. However, no new parameter is estimated by this procedure. It 1s straightforward to write down the likelthood function for the full model and so achieve full efficiency in deriving the estimates.

The labor supply function implied by the linear specification for $M$ associated with equilibrium on segment $R_{2} Z$ is

$$
\mathrm{H}_{(2)}=\mathrm{H}\left(\mathrm{R}_{2}, \mathrm{~W}_{2}, \nu\right)=a_{0}+a_{1} R_{2}+a_{2} W_{2}-\frac{\nu}{\mathrm{m}_{2}}
$$

where $a_{0}=-\frac{m_{0}}{\mathbb{m}_{2}}, a_{1}=-\frac{\mathbb{m}_{1}}{m_{2}}$, and $a_{2}=\frac{1}{m_{2}}$. For branch $\mathrm{ZN}$, it is

$$
H_{(4)}=E\left(R_{4}, W_{4}, v\right)=a_{0}+a_{1} R_{4}+a_{2} w_{4}-\frac{v}{m_{2}} .
$$


Thus, expected hours of work of a consumer whose equilibrium is on interval $R_{2}$ is

$$
E\left(B_{(2)} \mid v_{2}^{*}<v<v_{3}^{*}\right)=a_{0}+\alpha_{1} R_{2}+\alpha_{2} W_{2}+E\left[-\frac{v}{a_{2}} \mid v_{2}^{*}<v<v_{3}^{*}\right) ;
$$

and expected hours of work of a consumer who is known to be on segment $2 \mathrm{~N}$ is

$$
E\left(E_{(4)} \mid v<v_{1}^{*}\right)=\alpha_{0}+a_{1} R_{4}+a_{2} \omega_{4}+E\left(-\frac{v}{m_{2}} \mid v<v_{1}^{*}\right) .
$$

Writing $E\left(-\frac{v}{m_{2}} \mid v_{2}^{*}<v<v_{3}^{*}\right)$ as $b_{2} \lambda_{2}$ and $E\left(-\frac{v}{m_{2}} \mid v<v_{1}^{*}\right)$ as $b_{4} \lambda_{4}$, equation (26) Luplies that expected hours of work is

$$
\begin{aligned}
& E(E)=\left(a_{0}+a_{1} R_{2}+a_{2} W_{2}+b_{2} \lambda_{2}\right)\left(F\left(v_{3}^{*}\right)-F\left(v_{2}^{*}\right)\right)+\bar{H}\left(F\left(v_{2}^{*}\right)-F\left(v_{1}^{*}\right)\right) \\
&+\left(a_{0}+a_{1} R_{4}+a_{2} W_{4}+b_{4} \lambda_{4}\right) F\left(v_{1}^{*}\right) \\
&= \bar{H}\left(F\left(v_{2}^{*}\right)-F\left(v_{1}^{*}\right)\right)+\alpha_{0}\left(F\left(v_{3}^{*}\right)-F\left(v_{2}^{*}\right)+F\left(v_{1}^{*}\right)\right)+a_{1}\left(R_{2}\left(F\left(v_{3}^{*}\right)-F\left(v_{2}^{*}\right)\right)+R_{4} F\left(v_{1}^{*}\right)\right) \\
&+a_{2}\left(W_{2}\left(F\left(v_{3}^{*}\right)-F\left(v_{2}^{*}\right)\right)+W_{4} F\left(v_{1}^{*}\right)\right)+b_{2} \lambda_{2}\left(F\left(v_{3}^{*}\right)-F\left(v_{2}^{*}\right)\right)+b_{4} \lambda_{4} F\left(v_{1}^{*}\right) .
\end{aligned}
$$

The empifical specification for hours of work implied by this analysis is

$$
\mathrm{H}=\mathrm{E}(\mathrm{E})+\varepsilon
$$

where $E(B)$ is given by (37) and $\varepsilon$ is a randomly distributed heteroscedastic error term with mean zero. This regression equation is estimated using a random sample of consumers; nonworkers are assigned $\mathrm{H}=0$. 
One does not necessarily require complicated nonlinear methods to estimate the parameters of (37). Assuming that $v$ is normally distributed, It is possible to estmate each of the $F(v)$ functlons by ordered problt analysis. Then one can form the product of the estimated $F(v)$ and the wage, tax, and income variables. Following a straightforward modification of the procedure of Feckman (1979), one can estimate $\lambda_{2}$ and $\lambda_{4}$ up to a factor of proportionality. Then regression of $t$ on these varlables will yield estimates of $a_{0}, a_{1}, a_{2}$, and the factors of proportionality on $\lambda_{2}$ and $\lambda_{4}\left(b_{2}\right.$ and $\left.b_{4}\right) .^{5}$

There is a cruclal implicit assumpion in the preceding estimation procedures: hours of work are not measured with error, so measured hours reflect true or desired hours. If this is not so, data on hours of work do not suffice to allocate ind1viduals to the correct branch of the budget constraint. The state of the world a consumer occupies can no longer be directly observed, and we confront a discrete data version of an errors in variables probiem. If we use data on $\mathrm{H}$ to assign individuals to various states of the world, the ordered probit estimates the wrong $F(\nu)$ functions. Suppose that true hours of work, $\mathrm{H}$, and measured hours, which we denote by $\mathrm{H}^{*}$, are related by the equation $\mathrm{H}^{*}=\mathrm{H}+\mathrm{e}$ where $\mathrm{e}$ is a disturbance representing measurement error which is distributed independently of $\mathrm{H}$ and all the explanatory variables. Then the probability that one observes $\mathrm{H}^{*}$ in a given interval is not the same as the probability that $H$ falls in that interval. ${ }^{6}$ For example, the probability that $\mathrm{H}=\overline{\mathrm{H}}$ is positive, but the probability that $H^{*}=\overline{\text { E }}$ is zero assuming e follows a continuous density function. Since we estimate the wrong $F(v)$ functions (by using ordered probit analysis) when assigning consumers to various states on the basis of their H*, the variables formed by multiplying estimated $F(v)$ functions with $W, t_{A}$, 
$t_{B}, R_{2}, R_{4}, \bar{k}$, and $l$ in equation (37) are measured with error which produces inconsistent parameter estimates.

Th1s measurement error problem only affects the proposed two-stage estimation technique. It does not lead to any serious complications in the above theory and empirtical speciftcations. The expression for $E(H)$ given by (37) is unchanged. Nowhere in its derivation do we require states of the world to be correctly observed. The equation for i* can always be written as

$$
\mathrm{H}^{*}=\mathrm{E}(\mathrm{H})+\mathrm{E}^{*}
$$

where $\varepsilon^{*}=\varepsilon+e$.

This observation immediately suggests how to avoid the errors in vartables problen discussed above in the two-stage procedure based on ordered probit analysis. Instead of using a two-stage procedure of the sort proposed above to estimate the hours of work function (by first predicting the $F(u)$ terms in equation (37) and forming variables using $F(v)$ for the second stage zegression), one should estimate equation (37) directly by nonitinear least squares, exploiting all of the restrictions of the model, to generate parameter estimates. The $v_{1}^{*}, v_{2}^{*}, v_{3}^{*}$ terms contafn parameters of the marginal rate of substitution function which are intimately linked with the parameters of the labor supply equation (see equation (28)). ${ }^{7}$ As we will see in the rext section, this principle is the technique used by Burtless-ïauswan in their analysis of labor supply and taxes.

Allowing for measurement error in hours of work causes no essential change in the general formulas describing labor 
supply presented above. As previously noted, the formulas for the probabilities of occupying each state are exactly the same. The formula for the uncondit1onal expected value of measured hours of work is the same as for true hours given by (37) except that $\mathrm{H}^{*}$ replaces $\mathrm{H}$. Expected values in this instance are computed by integrating $F_{(i)}$ over the set $\theta_{i}$ and the sample space of the measurement error component of hours using the joint density of $v$ and the measurement error component.

Two important assumptions matntained in this section are that data on potential wage rates are avallable for all individuals including nonworkers and that wage rates are exogenous vartables. Relaxtng these assumptions does not introduce major complications in the previous analysis. Suppose that true market wage rates are generated by the function (40)

$$
W=W(Q, n)
$$

where $Q$ includes a congumer's measured characteristics, and $n$ is an error term representing the contribution of unmeasured characteristics. Conditions (17) $-(20)$ still determine the state of the world a consumer occupies. Replacing $W$ by $W(Q, \pi)$, we see that these condftions divide the sample space of $(\nu, n)$ Into subsets assoclated with each state of the world; they define the sets $\theta_{i}$ such that $(u, n) \in \theta_{i}$ 1mplies the consumer is in state $i$, and the probability of such an event is

$$
\text { Prob }\left((v, n) e \theta_{i}\right)=\iint_{\theta_{i}} k(v, n) d v d n
$$

where $k(\nu, \eta)$ is the joint density of $v$ and $n$, and integration fs carried out over the set $\theta_{1}$. 
The labor supply functions assoctated with each state are unchanged except that $W(Q, \pi)$ replaces $W$ in constructing the arguments of the functions for states 2 and 4 given by (2I) and (22). 8 The expression for expected hours of work given by (26) becomes

$$
E(H)=\sum_{i=1}^{4} E\left(H_{(i)} \mid(v, \pi) \in \theta_{i}\right) \operatorname{Prob}\left((v, \pi) \in \theta_{i}\right)
$$

where

$$
E\left(H_{(1)} \mid(\nu, n) e \theta_{1}\right)=\frac{\iint_{\theta_{1}} H(i) k(\nu, \eta) d v d \eta}{\operatorname{Prob}\left((\nu, n) E \theta_{1}\right)} .
$$

To 11lustrate the problems that arise when one introduces a wage function, consider combining a wage function of the form

$$
W=B_{0}+B_{1} Q+\pi
$$

whth the linear specification of the marginal rate of substitution function used above to develop the empirical model of labor supply given by (37) and (38). Even if we assume that $v$ and $n$ follow a joint normal distribution, an ordered probit analysis which allocates individuals to different states of the world no longer applies. While the conditions defining states given by $(17)-(20)$ imply restrictions on linear combinations of $v$ and $i$, it is not possible to construct a single linear combination of $v$ and $n$ whose value completely determines which state a consumer occupies.

In particular, define $\bar{W}$ as $E(W)$ (i.e., $\bar{W}=B_{0}+B_{1} Q$ ), and $\bar{R}_{4}=E\left(R_{4}\right)$. Replacing W with $\vec{W}$ and $R_{4}$ with $\bar{R}_{4}$ in equations (28), we see that 
three randomly distributed error terms $\omega, \phi_{A}$, and $\phi_{B}$ defined by $w=$ $v-n\left(1-t_{A}\right), \phi_{A}=v-n\left(1-t_{A}\right)+m_{1}\left(R_{4}-\bar{R}_{4}\right)$ and $\phi_{B}=v-n\left(1-t_{B}\right)+$ $\mathrm{m}_{1}\left(\mathrm{R}_{4}-\overline{\mathrm{R}}_{4}\right)$ determine a consumer's state of the world. According to conditions $(17)-(20)$, a consumer is in state 1 if $\omega \geq \bar{W}\left(1-t_{A}\right)-m_{0}-m_{1} R_{2} \equiv \omega^{*}$; In state 2 if $\omega<\omega^{*}$ and $\phi_{A}>\bar{W}\left(1-t_{A}\right)-m_{0}-m_{1} \bar{R}_{4}-m_{2} \bar{H} \equiv \phi_{A}^{*}$; in state 3 if $\phi_{A} \leq \phi_{A}^{*}$ and $\phi_{B} \geq \bar{W}\left(1-t_{B}\right)-m_{0}-m_{1} \bar{R}_{4}-m_{2} \bar{H} \equiv \phi_{B}^{*} ;$ and in state 4 if $\phi_{B}<\phi_{B}^{*}$. We see then, that the values of three different random variables (1.e., $w, \phi_{A}$ and $\phi_{B}$ ) determine occupancy of a state. Also, occupancy of either gtate 2 or 3 requires the simultaneous satisfaction of two conditions. Thus, while univarlate probit analysis can be used to predict the probabilfty of state 1 or 4, bivartate problt analysis is needed to specify the probability of state 2 or 3 .

Modtfying the expressions for expected hours of work to account for the linear wage function is stralghtforward using the notation of the previous paragraph. The labor supply functions for state 2 and for state 4 given by (33) and (34) become $B_{(2)}=a_{0}+a_{1} R_{2}+a_{2} \vec{W}\left(1-t_{A}\right)-\frac{\omega}{m_{2}}$ and ${ }_{(4)}=\alpha_{0}+a_{1} \bar{R}_{4}+\alpha_{2} \vec{W}\left(1-t_{B}\right)=\frac{\phi_{B}}{m_{2}}$. Thus, expected hours conditional on being in state 2 and in state 4 given by (35) and (36) become

$$
\begin{aligned}
E\left(H_{(2)} \mid \omega<\omega^{*} \text { and } \phi_{A}>\phi_{A}^{*}\right)= & \alpha_{0}+a_{1} R_{2}+a_{2} \bar{W}\left(1-t_{A}\right) \\
& +E\left(-\frac{\omega}{m_{2}} \mid \omega<\omega^{*} \text { and } \phi_{A}>\phi_{A}^{*}\right)
\end{aligned}
$$

and

$$
E\left(E_{(4)} \mid \phi_{B}<\phi_{B}^{*}\right)=\alpha_{0}+\alpha_{1} \bar{R}_{4}+\alpha_{2} \bar{W}\left(1-\tau_{B}\right)+\varepsilon\left(-\left.\frac{\phi_{B}}{m_{2}}\right|_{B}<\phi_{B}^{*}\right) .
$$


The labor supply functions associated with states 1 and 3 are unchanged. Given these new expressions for expected hours and the probabilities of occupylng each state, one can easily modify expression (37) for the uncondtional expected value of hours of work by makfing the approprtate substitutions.

Substituting this.new expression for $E(B)$ into the regression equation given by (38) creates an estimatiog equation for labor supply which allows wages to be endogenous and which does not require that wage offer data be avaflable for all observations. This new specification can be estimated using the noclinear least-squares procedure described above. To 1dentify all the parameters, one must also estimate the wage equation using daca on workers, adjusting for sample selection bias. This ts accomplished by regressing $W$ on $E(W \mid$ consumer vorks $)=B_{0}+B_{1} Q+E\left(n \mid \omega>\omega^{*}\right)$ where $E\left(\eta \mid \omega>\omega^{*}\right)$ can be computed using techniques proposed by Eeclenan (1979). It is also pogsible to estimate hours and wage equations jointly.

It Is sigatficant to aote that $\eta$ here repregents the contribution of unobserved vartables affecting true wages; it does not 1nclude a measurement error component for wages. Allowing for measurement errors in wages requireg exactly the same type of adjustment in the formulas for probabilities and expected values as is required in treating measurement errors in hours. The formulas for probabilities and expected values given by (41), (42), and (43) remaln valfd when measurement exror in wages is present, except that expected values are now computed by integrating H $_{(1)}$ times the 


\section{$-39-$}

joint denstey function of $v, \dot{\eta}$, and the measurement error components over the set $\theta_{1}$ and the sample space of the measurement error components. 


\section{A General Treatment of Taxes and Labor Supoly}

This section formulates a model of hours of work that allows for regressive as well as progressive taxes. Here we develop a methodology to handle cases where local marginal comparisons do not fully characterize labor supply behavior followlng suggestions by Burtless and Hausman (1978), Bausman (1979), and Wales and Woodland (1979).

A regressive cax scheme leads to a budget set that is not convex. Figure 4 displays the case we consider here. ${ }^{1}$ A marginal tax rate of $t_{A}$ applies to the branch $R_{2} 5$, and a lower inarginal zate $t_{B}$ applies to the branch SN.

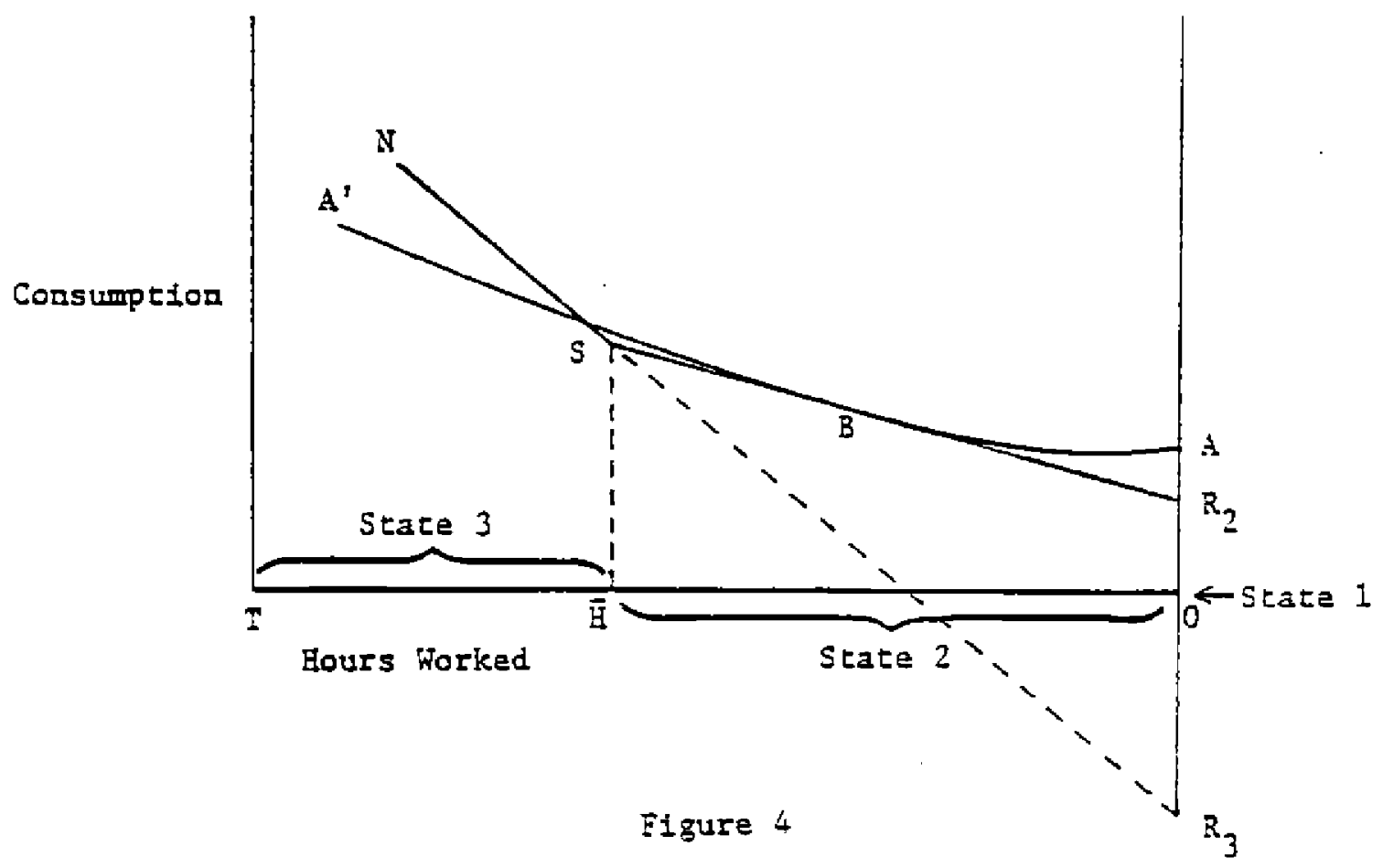


A consumer facing this budget set may choose any one of three possible states of the world: the no work position at kink point $R_{2}$ (1.e., state 1 ), or an interior equilibrium on efther segment $R_{2} S$ or segment SN (1.e., states 2 and 3$).^{2}$. A consumer in state 1 recelves initial after-tax income $R_{2}$. In state 2, a congumer recetves unearned income $R_{2}$ and works at an after-tax trage rate equal to $W_{2} \equiv W\left(I-t_{A}\right)$ where $W$ is the gross wage. Finally, a consumer in state 3 earns after-tax wage rate $W_{3} \equiv W\left(1-t_{B}\right)$ and can be vlewed as recetving the equivalent of $R_{3}$ as unearned 1ncome.

The analysis of kirked-donconvex budget constralnts involves an idea already considered in the analysis of fixed costs: a local comparison between the reservation wage and the market wage does not adequately characterlze the work-no work dectsion. Due to the nonconvextty of constraints, extstence of an Interior solution on a branch does not imply that equilibrium w111 occur on the branch. Thus in F1gure 4, point B assolcated with indifference map $A A^{\prime}$ is a posstble tntertor equilibrium on branch $R_{2} s$ that is clearly not the global optimin. Since local comparisons of the marginal rates of substituction function and after-tax wage rates cannot be used to determine the state of the world a consumer occupies, some features of the model developed in the previous section no longer apply.

An alternative strategy for deteralning the portion of the budget constratint on which a consumer decides to locate is the following. Write the direct preference function as $U(X, I, Z \alpha, v)$ where the exogenous variable $Z$ represents the measured charactertstics of a consumer, $\alpha$ is an unknown vector of parameters, and $v$ represents the unmeasured characteristics of a congumer that affect preferences. Using well-known methods, one may form the 1ndirect proference function $V(R, W, Z q, v)$. For interior solutions, labor supply functions may be written as 


$$
\mathrm{H}=\frac{\mathrm{V}_{\mathrm{W}}}{\mathrm{V}_{\mathrm{R}}}=\mathrm{H}(\mathrm{R}, \mathrm{W}, 2 \alpha, v) \text {. }
$$

While the argumencs of the functions $\square(\cdot), \nabla(\cdot)$, and $E(\cdot)$ way differ across consumers, the functional forms are assumed to be the same for each consurer. If a consumer is at an Intertor equilibrtum on either segment $R_{2} s$ or SN, then the equilibrium is defined by a tangency of the indifference curve and the budget constraint. Since this tangency indicates. a point of raximum attalnable utility, the indifference curve at this point represents a level of utility given by $\nabla\left(R_{1}, W_{1}, Z_{\alpha}, v\right)$ where $R_{1}$ and $W_{1}$ are respectively the aftertax unearned tocome and wage rate associated with segment 1 . Thus, hours of work at such a point must be given by $\nabla_{W} / V_{R}$ evaluated at $R_{1}$ and $W_{1}$. For this point to be an admissible solution, the tmplied hours of work must lie between the two endpoints of the 1nterval (1.e., equilibrium must occur on the budget segment). A consumer chooses not to work if utility at kirk $R_{2}$, $J\left(R_{2}, I, Z a, v\right)$, is greater than both $\nabla\left(R_{2}, W_{2}, Z a, v\right)$ and $v\left(R_{3}, w_{3}, Z a, v\right)$, provided that these latter utility values represent solutions located on the budget constraint.

We have, then, a general techntque for dividing the sample space of the "taste" component $v$ into the different reglons representing the various states. Define the labor supply functions $\mathrm{E}_{(1)}, \mathrm{E}_{(2)}$ and $\mathrm{E}_{(3)}$ as $\mathrm{E}_{(1)}=0$ and

$$
E_{(1)}=\frac{\nabla_{F}\left(R_{1}, w_{1}, Z \alpha, v\right)}{\nabla_{R}\left(R_{1}, W_{i}, Z a, v\right)}=\mathrm{B}\left(R_{1}, w_{1}, Z \alpha, v\right), \quad \pm=2,3 ;
$$

and define the admissible utility levels $v_{(1)}, \nabla_{(2 \gamma}$ and $\nabla_{(3)}$ as $v_{(1)}=$ $U\left(R_{2}, T, Z a, v\right)$, assumed to be greater than zero, and 
(46)

$$
\nabla_{(2)}=\left\{\begin{array}{cl}
V\left(R_{2}, W_{2}, Z_{\alpha}, v\right) & \text { if } 0<H_{(2)} \leq \bar{H} \\
0 & \text { otherwise }
\end{array}\right.
$$

and

$$
\nabla_{(3)}=\left\{\begin{array}{cl}
V\left(R_{3}, W_{3}, Z \alpha, v\right) & \text { if } \bar{H}<H_{(3)} \leq T \\
0 & \text { otherwise. }
\end{array}\right.
$$

A consumer whose $v$ lies in the set

$$
\theta_{1}=\left\{v: \nabla_{(1)} \geq v_{(2)} \text { and } v_{(1)} \geq v_{(3)}\right\}
$$

will aot work and occupies state 1 . If $v$ lies in the set

$$
\theta_{2}=\left\{v: \nabla_{(2)}>\nabla_{(1)} \text { and } \nabla_{(2)}>v_{(3)}\right\}
$$

a consumer is at an interfor solution on segment $R_{2} S$ and occupies state 2 . Finaliy, a consumer is at equilibrium in state 3 on segment SN if $v$ is an element of the set

$$
\theta_{3}=\left\{v: v_{(3)}>v_{(1)} \text { and } \nabla_{(3)}>v_{(2)}\right\} \text {. }
$$

The sets $\theta_{1}, \theta_{2}$, and $\theta_{3}$ do not intersect, and their union ts the sample space of $v$; thus, these sets are mutually exclusive and exhaustive. The functions $a_{(1)}$ determine the hours of work of an individual whose $v e \theta_{1}$. Given these definitions of the sets $\theta_{i}$ and the labor supply functions I(1), the analysis of the previous section applies with full force. Assuming 
$f(v)$ represents the distribution of tastes in the population, the formula for the probability of a consumer occupying state 1 given by (24) and the formulas for the conditional and the unconditional expected values of labor supply given by (25) and (26) all remain valid. While the sets $\theta_{i}$ may be difficult to specify in analytical form, the general theory and estimation procedures discussed in the previous section can'be applied to analyze the models considered in this section as well. This includes the theory and the estimation procedures relating to the introduction of a wage function or arbitrary forms of measurement erfor in hours of work and wages.

If wage rates are determined by the function given by (44), where $n$ reflects a randamly distributed exror term affecting true market wages, then the definitions

$$
\theta_{1}=\left\{(\nu, \pi): \nabla_{(1)} \geq v_{(j)} \text { for all } j, j \neq 1\right\}
$$

replace the charactertization of the sets $\theta_{1}$ given by (48)- $(50)$. A consumer whose $(v, n) \in \theta_{i} \quad$ chooses to occupy state $i$. Given these new defintions of $\theta_{i}$, the formulas for probabilities of occupying various states given by ( $4 I)$, and the formulas for expected values of labor supply given by (42) and (43) all apply without modification. If an errors in the variables problem excists for hours of work and wages, these formulas still apply except in computing the appropriate expected values it is also gecessary to frclude integration over the measurement error components of hours and wages. Burtless and Hausman (1978), Hausman (1979), and Wales and Woodland (1979) in thelr work on labor supply and taxes each use a variant of the 
general framework described above. All of these studies assume that hours of work are measured with error, and none of them treat wages as endogenous or measured with error. ${ }^{3}$

Burtless and Hausman assume a spectflc utflity function that is monotonic in the unobserved component $v$, and for which all consmers are guaranteed to work. In terms of the above model, a congumer occupies elcher state 2 or state 3 (1.e., the probabilicy of occupping state 1 is zero). For their preference function, there exists a critical value $v^{*}$ such that at that value, given the wage rate, tax rate, and intercept income components, the consumer is in equilibrium on both branches. Working with the indirect ut1lity function, $v, v^{*}$ is defined such that

$$
v_{(2)}=\nabla\left(R_{2}, W_{2}, Z \alpha, v^{*}\right)=\nabla\left(R_{3}, W_{3}, Z \alpha, v^{*}\right)=\nabla_{(3)}
$$

and for their spectal functional form a unique solution for $v^{*}$ is guaranteed to extst. For values of $v$ less than $v^{\star}$ the consumer is in equilibrium on branch one. For values of $v$ greater than $v^{\star}$, the consumer is on branch two. Thus, $\nu^{*}$ defines the sets $\theta_{2}$ and $\theta_{3}$, and in this instance these sets are intervals of the real line.

Given theis functional form for $\nabla$, hours of work equations are defined by Roy's 1dentity (see equatioc (45)). In the Burtless and Hausman world of two working states, the formula for expected labor supply given by (26) may be written as

$$
E(H)=\int_{-\infty}^{v^{*}} H_{(2)} f(v) d v+\int_{v^{*}} H_{(3)} f(v) d v .
$$


Burtless and hausman estimate the parameters of their model using maximum likelihood procedures. Allowing for measurement error in hours of work, they assume that this measurement error and $v$ are independenty distributed normal randow vartables. Thelr procedure, hottever, may be incerpreted as employing the nonlinear least squares method described in the previous section. In particular, letting $\mathrm{H}^{*}$ denote measured hours of work, the criterion

$$
\Sigma\left(R^{*}-E(H)\right)^{2}
$$

is minimized with respect to the parameters of $f(v)$ and the parameters of the utility function (which, of course, are also parameters of the labor supply function). Notice that the value of $v^{*}$ changes with values of wages, taxes, unearned income, a consumer's measured characterfstics, and the parameters of the preference function. Thus $v^{*}$ must be updated in any computational algorfthm that determines the parameters of the model. Assuming normaliy distributed optimization error, this criterion is also a maximum likelshood criterion.

Hausman (1979) extends this procedure to allow for corner equilibrium at zero hours of work. Since we have already discussed the essential featuzes of Hausman's model in Section III on Elxed costs, we will not repeat that discussion here. As noted in that section, there is a serfous problem with Hausman's agalysis concerning his treatment of unobserved wages. To deal with the problem of missing wage rates for nonworkers, Hausman introduces a wage function of the sort considered above. He falls, however, to account properly for the presence of unobserved components of wages when constructing 
the sets $\theta_{1}$ which defire states of the world (see formulas (51)). Hausman estimates parameters of a wage equation corrected for censoring, and then treats che predicted values from this equation as if they were the true values of wages. . This procedure is equivalent to assuming that the unobserved components of wages denoted above by $n$ (see equation (44)) are identically equal to zero for all individuals in the sample. Thus, he defines the $\theta_{1}$ sets only over the sample space of $v$, the random component reflecting differences in consumer's "tastes." This leads to tmproper definitions of these sets if there are any unobserved random components determining wage rates, and this is true even $1 f v$ and $n$ are independently distributed. The result is inconsistent estmates of the parameters of the preference and the labor supply functions.

The analyses of Burtless-Hausman and Hausmen depend cruclaily on particular functional forms for preferences. For a general specifteation of preferences, and unobserved components, the indirect utility function, $\nabla$, need not be monotonic in $v$. More cruclally, we are not guaranteed that a $v$ * satisfying equation (52) extsts, or if one does exdst, that it is unique; in this case the sample space of $v$ cannot be simply partitioned into regions assoctated with equilibrtum along different branches.

In contrast to the above studies, Wales and Woodland (1979) do not allow for unmeasured random differences in consumer's "tastes." In particular, the distribution of $v$ is assumed to be degenerate at a single point. This implies that the direct and the indirect preference functions and the labor supply function no longer depend on $v$; they reduce to $U(X, L, Z \alpha), V(R, W, Z \alpha)$, and $H(R, W, Z a)$. Thus, preferences and labor supply behavior alffer across consumers only to the extent that there are differences in measured characteristics. 
In terms of the general framework described above, the Wales-Woodland model can be 1nterpreted as one in which the probability of occupying one of the states is one and is zero for all other states. In fact, once a consumer's measured charactertstics, wage rate, and unearned income are known, there is no uncertainty regarding his exact location on the budget constraint. Since the varlables $R, W$, and $Z \alpha$ exactly determine a consumer's state of the world, the expression for the unconditlonal expectation for hours of work given by (37) becomes.

$$
E(B)=\left\{\begin{array}{llll}
{ }_{(1)} & \text { if } & (R, W, Z \alpha) & \text { imply state } 1 \\
\mathrm{H}_{(2)} & \text { if } & (\mathrm{R}, W, \mathrm{Z} \alpha) & \text { imply state } 2 \\
\mathrm{~B}_{(3)} & \text { if } & (\mathrm{R}, W, \mathrm{Z} \alpha) & \text { imply state } 3 .
\end{array}\right.
$$

Each $E_{(i)}$, then, is a nonstochastic function of $R, W$, and $Z$ a that is valid for only certain combinations of these variables. For other combinations, $E(B)$ shifts to a different $B_{(j)}$ function associated with the state impiled by the new comblations of observed variables.

The Wales-woodland estimation procedure is to choose the parameters of the preference function to minimize

$$
\Sigma\left(H^{*}-E(B)\right)^{2}
$$

Where the sumbation is over consumers, and $\mathrm{B}^{*}$ is measured hours of work (which need not be the same as true hours of work, H). By searching over potential values of the parameters of the preference function, one chooses the set of values that minimizes the above least squares criterion. In 
computing the value of this criterion (for a given set of parameter values), the following procedure is used to choose the labor supply function (i.e., $E$ (i)) relevant for each consumer.

Given the functional form for preferences, the exogenous variables of the model (1.e., a consumer's measured characteristics), and values for the parameters of the preference function, one can compute the utilicy of the consumer at each point of the budget constrafnt-1n particular, along each branch and at each kink point (Including the no-work point $\mathrm{R}_{2}$ ). By checking utility on each branch and verffying the existence of an interior solution, and by checklng utiltty at each kink, one can literally solve the consumer's maximization problem by choosing that labor supply function associated with the highest uttlity. For each set of values for the parameters of the utility function, it is posstble to calculate the unique equilibrium position, either 1nterfor or corner, for each consumer. As the parameter values change, the computed equilibrium hours of work changes.

When taxes are progressive (the only case Wales-Woodland consider), this procedure botls down to the following algortthm. For each value of $\alpha$, one can compute the hours of work lmplied for each branch using the labor supply function assoclated with that branch implied by Roy's Idencity. Thus, for the firgt branch (1.e., state 2) hours of work are given by ${ }_{(2)}{ }^{*}$ If the predicted $\mathrm{B}_{(2)}$ lies in the interval $(0, \overline{\mathrm{B}} \mathrm{J}$, the consuner's equilibrium position is assumed to lie along the first branch and $E(B)$ is set equal to $\mathrm{B}_{(2)} \cdot$

Suppose that for the particular value of a under consideration, (2) $_{(1 \text { ) }}$ ourside the interval $(0, \overrightarrow{\mathrm{H}})$, then the equilibrium postion is not on the flist branch; so, one checks the second branch. For the same a, one can 
compute the implied hours of work for this branch, $\mathrm{H}_{(3)}$. If the $\mathrm{H}_{(3)}$ lies in the interval ( $\vec{H}, \mathrm{I}]$, the consumer is assumed to be in equilibrium at an interior point on the second branch, and $E(H)=H_{(3)}$. Otherwise he is not. The same procedure can be used for a problem with moge than two branches. Frow convexty of preferences and constraints, for each $a$, equilibrium can occur on only one branch at most.

Suppose that we never predict an th that lies in the correct interval. This can happen if there is a corner equilibriun. Each corner should then be checked including the nowork corner. Evaluate $U$ at each corner. Pick the corner with the highest utility. This is the equilibrium value, and $E(H)$ is set equal to that labor supply function associated with the kink. This procedure is guaranteed to locate the consumer's optimum for each value of a. This procedure is immodest in that it assumes that given $\alpha$, the econometrician can solve the consumer's problem as well as the consumer can. There is no information the consumer has that is relevant to selecting his desired hours of work that the econometriclan does not know as well. There are no omtited variabies in the model. Moreover, the wodel assumes that all consumers have the same $a$.

These are strong assumptions. If there are such onitted variables, or if a differs across congumers, the Wales-Woodland procedure generates inconsistent parameter egtimates because their procedure can allocate consumers to the wrong branch of the budget constraint. Surptisingly, less restrictive assumptions that allow for random differences in unmeasured traits affecting "tastes" may lead to a simpler est1mation scheme, such as the one proposed by Burtless and Hausman outlined above. 
VI. Conclusion

The Index function framework forms the bagis for

wuch of the recent work on labor supply. The use of this framework provides a corventent approach for the estimation of hours of tork functions when budget constralats constst of several segments and kfoks. The methodology presented in the last. section is the most general. It not only admits both convex and non-convex constraint sets, it also allows for the endogeneity of wage rateg, for the absence of wage data for some of the sample observattons, and for arbitrars forms of measurement error in hours of work and wages. 


\section{APPENDIX}

\section{The Performance of Various Estinators in} the Presence of Samole Selection Bias

Woodland and Vales (1978) report some sampling experiments with alternative estimators for labor supply and wage equations in the presence of sample selection bias. The model they consider is a variant of teckman (1974a).

Their hours of work equation is

$$
\begin{array}{ll}
h=b_{0}+\beta_{1} w+\beta_{2} x_{2}+u & \text { if } h>0 \\
h=0 & \text { otherwise. }
\end{array}
$$

Their wage function is

$$
w=Y_{0}+r_{1} z_{1}+Y_{2} z_{2}+e .
$$

Wages are observed only if $h>0$. In their sampling experiments $u$ and $e$ are assumed to be mean zero normally distributed variables with variances $\sigma_{u}^{2}$ and $\sigma_{e}^{2}$ sespectively and interecuation correlation of $n$.

The following methods are compared: (a) ordinary least squares (OLS); (b) maximum 1ikelihood; (c) Amemiya's estimator (1973); (d) nonifnea: least squares; (e) Heckman's maximum likelihood estimator (1974); (f) Heckman's two stef estimator (1976, 1979). For a complete and thoroughly conpetent discussion of these estimators, see Wales and 1 footland (igi3). Table 1 reports on estinators based on samples of 5000 individuals. The number of norkers is incicated by 14 . The stue parameters are given in the first colum. Least scuares zesults are shown in the second column to be badly biased. The waximu likelihood estimators (method 1 and method $i$ ) generate estinates auite close so the 
true values. Amemiya's procedure (method 2) and a one round iterate of Amemiya (method $2 A$ which is one-Newton step toward the likelihood optimim frow the initial consistent Amemiya estimator) is badly behaved. A nonlinear least squares procedure (method 5) produces estimates that are badly biased.

Essentially the same results are found for estimators that use the entire sample (see Table 2), OLS is badly biased. Maximum Iikelihood (method 4) generates estimates quice close to the true values. Two stage methods are less precise in generating parameter estinates. Corrections for selection bias in the wage equation (results reported in Table j) suggest that the two stage procedures and the maximus likelihood procedure do about equally well, bue naximum likelihood is still rarginally better.

It is important to note that these samples are generated under ideal conditions. It would be very interesting to compare the perfomance of these estimatcrs, which are based on the normality assumption, in the situation in which the errors are nonnormal. It seems likely that the two stage estimators are more robust because the conditional means of the ersors may still closely approximate the true conditional mean (i.e., the $g$ ters in equation (5)). Little is known about the perfornance of these estimators in the presence of other model misspeciticarions, but by analogy with the findings in the simulzaneous equation liferature it is likely that the two stage estimators are more robust so misspecification than are the maximum likelihood estinators. 
TABLE 1: HOURS EOUATION ESTIMATES BASED ON THE SUD-SAMPLE OF WORRERS

True OLS Method 1 Method 2 Method 2A Method 3 Misthod 7 $\underline{p}=0 \cdot(H=1634)$

$\begin{array}{cccccccc}\varepsilon_{0} & -1.1854 & . .359 & -1.027 & -.185 & -.508 & -.591 & -1.083 \\ & & (.044) & (.120) & (.358) & (.080) & & (.115) \\ \varepsilon_{1} & 1.0 & .596 & .943 & .790 & .840 & .847 & .955 \\ & & (.017) & (.034) & (.066) & (.026) & & (.038) \\ \varepsilon_{2} & 1.0 & .625 & .987 & .841 & .835 & .889 & 1.011 \\ & & (.026) & (.047) & (.077) & (.037) & & (.042) \\ \sigma_{u} & 1.2472 & .983 & 1.232 & .925 . & 1.057 & 1.035 & 1.234 \\ & & & (.033) & (.160) & (.021) & & (.034)\end{array}$

\begin{tabular}{|c|c|c|c|c|c|c|c|}
\hline \multirow[b]{2}{*}{$\stackrel{2}{0}_{0}$} & \multicolumn{7}{|c|}{$(H=1581)$} \\
\hline & -7.1854 & $\begin{array}{l}-.073 \\
(.042)\end{array}$ & $\begin{array}{r}-1.243 \\
(.095)\end{array}$ & $\begin{array}{r}-? .691 \\
(.453)\end{array}$ & $\begin{array}{l}-.725 \\
(.053)\end{array}$ & -1.430 & $\begin{array}{r}-1.103 \\
(.093)\end{array}$ \\
\hline$s_{1}$ & 1.0 & $\begin{array}{l}.822 \\
(.018)\end{array}$ & $\begin{array}{l}1.157 \\
(.031)\end{array}$ & $\begin{array}{l}1.256 \\
(.024)\end{array}$ & $\begin{array}{l}1.037 \\
(.023)\end{array}$ & 1.211 & $\begin{array}{r}.994 \\
(.033)\end{array}$ \\
\hline 2 & 1.0 & $\begin{array}{l}.744 \\
(.022)\end{array}$ & $\begin{array}{l}1.057 \\
(.037)\end{array}$ & $\begin{array}{l}1.115 \\
(.096)\end{array}$ & $\begin{array}{l}.069 \\
(.028)\end{array}$ & 1.096 & $\begin{array}{l}1.016 \\
(.027)\end{array}$ \\
\hline$E_{u}$ & 1.0393 & .853 & $\begin{array}{l}.097 \\
(.024)\end{array}$ & $\begin{array}{l}1.139 \\
(.137)\end{array}$ & $\begin{array}{l}.855 \\
(.016)\end{array}$ & 1.062 & $\begin{array}{l}1.011 \\
(.026)\end{array}$ \\
\hline & & & $2=-0$. & $(i n=$ & 26) & & \\
\hline$=0$ & -1.1854 & $\begin{array}{l}.850 \\
(.044)\end{array}$ & $\begin{array}{c}-1.071 \\
(.179)\end{array}$ & $\begin{array}{l}.237 \\
(.659)\end{array}$ & $\begin{array}{l}-.146 \\
(.095)\end{array}$ & -.347 & $\begin{array}{r}-1.225 \\
(.160)\end{array}$ \\
\hline$E_{1}$ & 1.0 & $\begin{array}{l}.339 \\
(.015)\end{array}$ & $\begin{array}{c}.595 \\
(.038)\end{array}$ & $\begin{array}{c}.529 \\
(.085)\end{array}$ & $\begin{array}{l}.564 \\
(.025)\end{array}$ & .578 & $\begin{array}{c}.959 \\
(.049)\end{array}$ \\
\hline 6 & 1.0 & $\begin{array}{l}.477 \\
(.029)\end{array}$ & $\begin{array}{l}1.010 \\
(.068)\end{array}$ & $\begin{array}{l}.771 \\
(.128)\end{array}$ & $\begin{array}{l}.819 \\
(.047)\end{array}$ & .849 & $\begin{array}{l}1.042 \\
(.063)\end{array}$ \\
\hline$\sigma_{u}$ & 1.7283 & 1.127 & $\begin{array}{l}1.594 \\
(.053)\end{array}$ & $\begin{array}{l}1.118 \\
(.231)\end{array}$ & $\begin{array}{l}1.280 \\
(.028)\end{array}$ & 1.314 & $\begin{array}{l}1.711 \\
(.057)\end{array}$ \\
\hline
\end{tabular}


Notes ro Table 1

Method 1 estinares are achieved by naximizing the conditional likelihood function for hours of work.

Method 2 is based on Amemiya's estimator for truncated samples (Amemiya, 1973).

Method $2 A$ is one-Newton-Raphson iterate of the likelihood function . used in method 1 using the Amemiya initial consistent estimator. Method $\mathbf{j}$ is a nonlinear least squares procedure that jointly estimates the parameters of the regression function and the conditional mean of the random sample disturbance (for details, see wales and Woodland, 1978, who propose this procedure).

Method 7 is Heckman's (1974a) maximm likelihood estimator for hours and wages conditioned for samples of workers. This escimator is proposed by Wales and Woodland (1978). 
INELE 2: HOLRS EQUATIOHY ESTIIIATES GASED ON THE ENTIRE SAMPLE

True OLS Method 4 Method 5A Mathod 5B Method 5C Method 5D

$$
\underline{n=0}
$$

\begin{tabular}{|c|c|c|c|c|c|c|}
\hline-7.1854 & $\begin{array}{l}.267 \\
(.075)\end{array}$ & $\begin{array}{r}-1.168 \\
(.053)\end{array}$ & $-.798,-.799$ & $-.945,-.946$ & $\begin{array}{l}-.782 \\
(.670)\end{array}$ & -.921 \\
\hline 1.0 & $\begin{array}{c}.398 \\
(.010)\end{array}$ & $\begin{array}{c}.984 \\
(.023)\end{array}$ & $.900, .876$ & $.947, .917$ & $\begin{array}{c}.883 \\
(.159)\end{array}$ & .921 \\
\hline 1.0 & $\begin{array}{l}.329 \\
(.011)\end{array}$ & $\begin{array}{l}1.028 \\
(.027)\end{array}$ & $\begin{array}{c}.931 \\
(.178)\end{array}$ & .963 & $\begin{array}{c}.927 \\
(.176)\end{array}$ & .956 \\
\hline 1.6934 & & $1.6847^{*}$ & $\begin{array}{l}1.476 \\
(.625)\end{array}$ & 1.538 & $\begin{array}{l}7.403 \\
(.676)\end{array}$ & 1.519 \\
\hline 1.2472 & .906 & $\begin{array}{l}1.246 \\
(.027)\end{array}$ & & & & \\
\hline
\end{tabular}

$$
\underline{0}=0.5
$$

$\begin{array}{cccccccc}B_{0} & -1.1854 & .243 & -1.217 & -1.481,-1.481 & -1.693,-1.694 & -1.491 & -1.663 \\ & & (.015) & (.040) & & & (.913) & \end{array}$

$\begin{array}{lllllllll}\therefore & 1.0 & .400 & 1.008 & 1.082,1.074 & 1.129,1.147 & 1.081 & 1.129\end{array}$

$\begin{array}{llllllll} & & (.010) & (.018) & & & (.219) & \\ B_{2} & 1.0 & .335 & 1.014 & 1.099 & 1.144 & 1.102 & 1.136 \\ & & (.011) & (.021) & (.222) & & (.221) & \\ H_{1} & 1.6934 & & 1.707^{*} & 1.822 & 1.987 & 1.830 & 1.904 \\ & & & & (.805) & .0302) & \end{array}$

$\begin{array}{llll}\text { iu } & 1.0393 \quad .909 \quad & 1.047 \\ & & (.021)\end{array}$

\begin{tabular}{|c|c|c|c|c|c|c|}
\hline-1.1854 & .271 & -1.207 & $-.569,-.569$ & $-.825,-.825$ & -.558 & -.823 \\
\hline & $(.015)$ & $(.074)$ & & & $(.650)$ & \\
\hline 1.0 & .370 & .957 & $.803, .801$ & $.875, .854$ & .802 & .854 \\
\hline & $(.009)$ & $(.032)$ & & & $(.151)$ & \\
\hline 1.0 & .321 & 1.024 & .860 & .927 & .860 & .827 \\
\hline & $(.011)$ & $(.031)$ & $(.167)$ & & $(.167)$ & \\
\hline 1.6534 & & $1.720^{\circ}$ & 1.260 & 1.457 & 1.268 & 1.455 \\
\hline & & & $(.591)$ & & $(.590)$ & \\
\hline
\end{tabular}

$\underline{c}=-0.5$

$\begin{array}{llll}1.7203 \quad .899 & 1.705 \\ & & & \\ & & 045)\end{array}$

tThis estirite is derived from the others. 
Notes to Table 2

Mechod 4 is Hecleman's (1974a) maximu likelihood estimator for hours and wages.

Method $5 \mathrm{~A}$ is the Heckmar (1976, 1979) indirect least squares two-step estimator. The mitiplicicy of estimates for $s_{1}$ arises because this parameter is overidentified in the current model.

Method $5 B$ is a GLS version of $5 A$.

Method SC is the Heckman procedure as modified by Wales and Woodland (1978) or Heckman (1978) to Iesolve the overidentification problem.

Method 50 is a GLS version of $5 C$.

" $\mu_{I}$ " is the estimated conditional mean of the disturbance cerd in the hours of work equation. (This corresponds to 8 in equation ( 5 ).) 
TABLL 3: WAGE EQUATION ESTIMATES

True OLS Method 4 Method 5A Miethod 5B Method 7 $\underline{0}=\underline{0}$

\begin{tabular}{|c|c|c|c|c|c|}
\hline \multirow[t]{2}{*}{$Y_{0}$} & .752 & -.030 & $=.043$ & -.049 & $\begin{array}{l}.024 \\
(.080)\end{array}$ \\
\hline & $(.034)$ & $(.045)$ & $(.106)$ & & \\
\hline \multirow[t]{2}{*}{1.0} & .780 & .997 & .993 & .993 & .964 \\
\hline & $(.026)$ & $(.026)$ & $(.039)$ & & $(.037)$ \\
\hline 1.0 & .821 & 1.019 & 1.026 & 1.030 & 1.011 \\
\hline & $(.025)$ & $(.026)$ & $(.039)$ & & $(.037)$ \\
\hline .7749 & & $.787^{*}$ & .802 & .807 & \\
\hline$\cdot$ & & & $(.128)$ & & \\
\hline 1.1455 & 1.044 & 1.160 & 1.164 & & 1.155 \\
\hline & & $(.024)$ & & & $(.027)$ \\
\hline
\end{tabular}

$\underline{0}=0.5$

$\begin{array}{lllllll}r_{0} & 0 & .783 & -.006 & .055 & .062 & .091 \\ & & (.025) & (.031) & (.089) & & (.058)\end{array}$

$\begin{array}{lllllll}\gamma_{1} & 1.0 & .794 & .979 & .970 & .967 & .974 \\ & & (.018) & (.018) & (.031) & & (.029)\end{array}$

$r_{2} \quad i .0$

$\begin{array}{lll}.781 & .987 & .055\end{array}$

.968

.968

$(.018)$

(.019) $\quad .(.032)$

$(.029)$

$\mu_{2} \quad .7749$

$.774 *$

.703

.707

e $\quad 0.9748$

.753

$(.107)$

$.913 \quad .882$

.878

(.019)

$(.023)$

$\underline{0}=-0.5$

\begin{tabular}{|c|c|c|c|c|c|}
\hline \multirow[t]{2}{*}{$Y_{0}$} & .760 & .043 & -.039 & -.030 & .048 \\
\hline & $(.048)$ & $(.068)$ & $(.140)$ & & $(.095)$ \\
\hline \multirow[t]{2}{*}{1.0} & .827 & 1.002 & 1.023 & 1.022 & 1.006 \\
\hline & $(.035)$ & $(.035)$ & $(.051)$ & & $(.047)$ \\
\hline \multirow[t]{2}{*}{1.0} & .814 & .981 & 1.000 & 1.004 & .988 \\
\hline & $(.037)$ & $(.0 .35)$ & $(.050)$ & & $(.047)$ \\
\hline \multirow[t]{2}{*}{$H_{2} \quad .7749$} & & $.728^{*}$ & .805 & .790 & \\
\hline & & & $(.152)$ & & \\
\hline \multirow[t]{2}{*}{1.6564} & 1.525 & 1.598 & 1.674 & & 1.593 \\
\hline & & $(-0.31)$ & & & $(.030)$ \\
\hline
\end{tabular}

- This estinate is derived from the otiners. 
Nores to Table 3

All of the procedures have been defined in Tables 1 and 2.

" $\mu_{2}$ " is the estimated conditional mean of the disturbance term in

the wage equation. 


\section{Footnotes}

\section{Section II}

${ }^{1}$ For expositional simplicity, we abstract from endogenous wages in the statistical analysis presented below. This assumpion is not essential to the analysis.

Defining $H_{W}=0$ for nonworkers, it is straightforward to verify that the partial derivative of expected hours with respect to $W$ from equation (11) exceeds the mean value of $\mathrm{H}_{\mathrm{W}}$ in the population. Defining $\mathrm{H}_{R}=0$ for nonworkers, if leisure is a normal good the partial derivative of expected hours with respect to $R$ is smaller than the mean value of $H_{p}$ in the population.

${ }^{3}$ To simplify notation, we supress $z_{2}$ (i.e., a consumer's measured characteristics) as an argument of the functions $\mathrm{U}(\cdot), M(\cdot)$ and $H(\cdot)$.

\section{Section III}

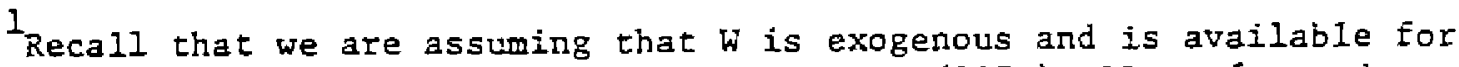
each individual in the sample exposition. Cogan (1979) allows for endogenous wages and his approach does not require wage data for nonworkers.

2 Because of the assumptions about functional forms, any set of exogenous variables, including those that enter the utility function in their own right, serve to identify the effect of fixed costs on hours of work. Thus, as a consequence of his functional form, Hausman does not require the exclusion restriction needed by Cogan to identify the effect of fixed costs on labor supply. 


\section{Section IV}

In this section, we abstract from the very important problem that true taxes are not measured by published cax schedules, even schedules that carefuliy set out exemptions and deductions. If consumers spend real resources to avoid paying taxes, such tax avoidance costs are properly considered as part of the effective tax. With the exception of preliminary work of Gould (1979), this problem has not received attention in the literature.

2.

Instruments will be available provided that variables appearing in the wage function do not appear in the structural labor supply function. Such variables are valid instruments.

${ }^{3}$ The procedure suggested by Hall (1973) and Rosen (1976) that evaluates the marginal tax rates and intercept terms at a standard number of hours of work for everyone in the sample, generates inconsistent parameter estimates because $E^{\prime}$ and $E$ - E't are evaluated at the wrong point.

4 However, we have no guarantee in this problew that the constraint set will be so characterized. See Rosen (1974).

Sellechio (1979) proposes estimating a model with kinked convex constraints in essentially chis fashion. 
Section IV (continued)

${ }^{6}$ Letting $g(e)$ denote the density function of e, these probabilities are related by the equation

$$
\text { Prob } \begin{aligned}
\left(C_{1} \leq H^{*} \leq C_{2}\right) & =\text { Prob }\left(C_{1} \leq H+e \leq C_{2}\right) \\
& =\int_{-\infty}^{\infty} \operatorname{Prob}\left(C_{1} \leq H+e \leq C_{2}\right. \text { le)g(e)de } \\
& =\int_{-\infty}^{\infty} \operatorname{Prob}\left(C_{1}-e \leq H \leq C_{2}-e \mid e\right) g(e) d e \\
& =\int_{-\infty}^{\infty} \operatorname{Prob}\left(C_{1}-e \leq H \leq C_{2}-e\right) g(e) d e
\end{aligned}
$$

where the last Iine follows from the independence assumption of $i$ and $e$.

7 It is clear that one need not rigidly chain the parameters of the hours of work function to the $F$ functions to secure identffication. Thus, one could estimate the parameters of equation (37) by restricting the parameters of the $F$ and $\lambda$ functions to be the same, and not exploiting the theory to generate the relationship between these parameters and $\alpha_{1}, \alpha_{2}$, and $\alpha_{3}$. However, even though the model is formally identified, it is likely that parameter egtimates obtained by this procedure would be imprecisely estimated. Exploiting all the restrictions of the theory requires making strong assumptions about functional form. But if these assumptions are not made, parameter estimates are likely to be imprecise.

8 Notice that the arguments $W_{2}, W_{4}$, and $R_{4}$ each depend on $W$.

Section V

iGeneralization to more than two branches involves no new principle. Constraint sets like $\mathrm{R}_{2} \mathrm{SZ}$ are common in negatfve lncome tax experiments and in certain social programs.

2 The kink at $S$ is not treated as a state of the world because there is not a positive probability that a consumer will be at this point if the "taste" component $v$ follows a continuous density. In fact, for most preference functions, point $S$ can never be an equilibrium.

3 Eausman (1979) introduces and estimates a wage equation, but, as we discuss later in this section, his estimation procedures do not properly treat unobserved components of wages. 
Amemiya, T. "Qualitative Response Models." Annals of Econonic and Social Measurement 4 (Sumerer 1975): 363-372.

- "Regression Analysis when the Dependent Variable is Truncated Normi." Econometrica (November 1973).

Ben-Porath, Yoram. "Labor Force Participation Rates and the Supply of Labor." Journal of Polltical Economy 81 (May-June 1973): 697-704.

Borjas, G., and Heckman, J. "Labor Supply Estimates for Public Policy Evaluation." Proceedings of the Thircy-first Annual Meeting of the Industrial Relations Research Center (1978): 320-33l.

Boskin, Michael J. "The Economies of Labor Supply." In Glen G. Cain and Harold W. Watts, eds., Income Maintenance and Labor Supply. Chicago: Markham, 1973.

Burtless, G., and Eausman, J. "The Effect of Taxation on Labor Supply: Evaluating the Gary Negative Income Tax Experimant." Journal of Political Economy 86, no. 6 (December 1978): 1103-1131.

Cain, G., and Watts, B. Income Mafutenance and Labor Supply. Chicago: Markham Publishers, 1973.

Cogan, J. "Fixed Costg and Labor Supply." The Rand Corporat1on, May I979. Econogetr1ca, Forthcoming.

. "Labor Supply with Time and Money Costs of Participation." The Rand Corporation, R-2044-HEW, October 1977.

DaVanzo, J.; Detray, D.; and Greenberg, D. "Estimating Labor Supply Response: A Sensitivity Analysis." The Rand Corporation, R-1372-OEO, December 1973.

Domenctch, M., and McFadden, D. Urban Travel Demand: A Behavioral Analysis. Amsterdam: North-Holland Publishing Co., 1975.

Gould, W. "Taxes and Female Labor Supply." Ph.D. dissertation, Unfversity of California, Los Angeles, 1979.

Gronau, Reuben. "Wage Comparisons-A Selectivity Blas." Journal of Polftical Econoury 82, (November-December 1974): 1119-1144.

HalI, Robert E. "Wages, Income and Jours of Work in the U.S. Labor Eorce." In Glen G. Cain and Harold W. Watts, eds., Income Maintenance and Labor Supoly. Chicago: Markham, 1973. 
Hanoch, G. "A Multivariate Model of Labor Supply: Mechodology for Estimation." Published as a Rand Report in 1976, and in J. P. Smith, ed., Female Labor Stuply: Theory and Estimation. Princeton, New Jersey: Princeton University Press, 1979.

Hausman, J. "The Effect of Wages, Taxes and F1xed Costs on Women's Labor Force Participation." Massachusetts Institute of Technology, May 1979.

Hausman, J., and Wise, D. "The Evaluation of Results from Truncated Samples: The New Jersey Negative Income Tax Experfment." Annals of Econowlc and Soctal Measurement 5 (Fall 1976): 421-446.

* "Socfal Experimentation, Truncated D1strfbutions, and Efffcient Estimation." Econometrica (May 1977): 919-938.

Heckman, J. "Shadow Prices, Market Wages and Labor Supply." Econometrlca (July 1974). (a)

" "The Effect of Child Care Programs on Women's Work Effort." Journal of Polftical Economy (March-Apeil 1974). (b)

- "The Common Structure of Statistical Models of Truncation, Sample Selection Blas and Limlted Dependent Vartables and a Simple Estimator for Such Models." Annals of Economtc and Soctal Measurement (December 1976).

. "Dumy Endogenous Variables in a Stmultaneous Equation System." Econometrica (July 1978).

- "Sample Selection Bias as a Specification Error." Econometrica (January 1979).

Johnson, T. "Qualitative and Limited Dependent Varfables fn Economic Relationships." Econometrica (May 1972): 440-455.

Lewis, B. Gregg. "On Income and Substitution Effects on Labor Force Partic1pation." Uatversity of Chicago, 1967.

"Interes del empleador en las horas de Trabajo del empleado" [Employer Interests in Employee Hours of Work]. Cuadernos de Economia, Catholle University, Ch1le, 1969.

McFadden, Dantel. "Quantal Choice: A Survey." Annals of Economic and Soc1al Measurement 5 (Fall 1976): 363-390.

- "Conditional Logit Analysis of Qualitative Choice Behavior." In P. Zaremba, ed., Frontiers in Econometries. Academic Press, 1974.

Pellech1o, A. "The Estimation of Labor Supply over Kinked Budget Constralnts: Some New Econometric Methodology." Working Paper \#337, National Bureau of Economic Research, Cambridge, August 1979.

Rosen, H. S. "Taxes in a Labor Supply :Todel with Joint Wage-Hours Determination." Econometrica (May 1976): 485-508. 
Rosen, S. "Hedonic Prices and Implicit Markets." Journal of Political Economy (January 1974).

Rosett, Richard N., and Nelson, Forrest D. "Estimation of the Two-Limit Probit Regression Mode1." Econometrica 43 (January 1975): 141-I46.

Smith, James P., ed. Female Labor Supply: Theory and Estimation. Princeton, New Jersey: Princeton Unfversity Press, forthcoming, 1981.

Tobin, J, "Estimation of a Model with Limited Dependent Variables." Econometrica (1958).

Wales, T. J., and Woodland, A. D. "Labour Supply and Progresstve Taxes." Review of Economic Studies 46 (January 1979): 83-95.

"Sample Selectivity and the Estimation of Labour Supply Functions." Untversity of Brifish Columbla, November 1978. 